\title{
Aportes y Desafíos de las Ciencias Sociales a la Organización y la Actividad Policial
}

\author{
Patricio Tudela Poblete (Ph.D.)
}

Academia Superior de Estudios Policiales

\& Universidade Do Chile - Chile

$$
\approx
$$

\begin{abstract}
RESUMEN
Se examinan algunos supuestos sobre la investigación de la policía y sus desafíos y se revisa el estado del arte desde las ciencias sociales, destacándose algunos de los principales temas de interés de los investigadores, los enfoques disciplinarios y aportes fundamentales de la sociología (de la policía), la psicología social y de la antropología (de una policía). Se intenta avanzar hacia la construcción de una síntesis y perspectiva común para la exploración de la policía y lo policial. Se pone especial atención en el estudio de la policía, como cultura organizacional y praxis cotidiana, subrayándose que en muchas ocasiones la cultura es más importante que cualquier otro factor, para ello se ilustra algunos rasgos. Finalmente, se formulan recomendaciones de cursos de acción a fin de promover la pesquisa interdisciplinaria y práctica para el desarrollo de la organización policial en la región y se sugiere una agenda de indagación de la cultura policial.
\end{abstract}

\section{INTRODUCCIÓN}

La indagación sobre la policía es una actividad emergente en América Latina. Ella tiene -al menos- dos vertientes. Una más desarrollada que la otra, pero ambas están aún en procesos embrionarios. La primera se perfila en universidades y desde las ciencias sociales, mientras que la otra se desarrolla al amparo de organismos dependientes de las propias instituciones policiales -a través de las academias-, pero esta es una actividad poco frecuente. Ambas convergen en desplegar estudios buscando promover mejoras en la actividad policial.

La investigación científica sobre la policía puede ser entendida como un proceso emergente, que configura una actividad particular, que busca la ge- 
neración y acumulación de conocimientos sobre la organización y la función policial, con la intensión de utilizar éstos en provecho de la sociedad. En rigor, podemos señalar que se trata de una pesquisa original, llevada a cabo con el objetivo de adquirir nuevo conocimiento, con una intención u objetivo práctico.

Lo específico de este tipo de pesquisas no radica en el empleo de algún método en particular, sino en el objeto de análisis: lo que la policía es $y$ hace. En cualquier caso, se aspira a que la actividad investigativa sea guiada por la racionalidad propia de la ciencia y, de la mismo manera, la certeza de que el conocimiento reunido es pertinente, confiable y objetivo - esto son, por cierto, atributos decisivos para la legitimidad de esta actividad-.

El objeto es lo verdaderamente relevante. El creciente interés por estudiar la organización policial y su labor obedece a la sentida necesidad de generar un conocimiento que permita construir respuestas a determinadas interrogantes, que requieren respuestas urgentes, y cubrir vacíos respecto de la praxis policial en un contexto social y político cada día más desafiante.

Es difícil encontrar organizaciones policiales que no revisen o no se estén reformulando su contribución a la seguridad. En las últimas tres décadas las policías han adquirido una relevancia de la que nunca habían gozado y se incorporan definitivamente al discurso social y político. Esa relevancia les obliga a reformularse a si mismas como una de las piezas clave de la sociedad y no como mero accesorio. Las policías no están al margen de los desarrollos propios de las sociedades contemporáneas y sus servicios -la seguridad pública y ciudadana- son tan fundamentales que ellas no se circunscriben hoy exclusivamente al ámbito judicial y penal. Las prácticas policiales y conductas de los policías son decisivas en el desarrollo de nuestras sociedades.

En efecto, no hay duda que, entre las distintas razones, la preocupación por la policía -como objeto de análisis y materia de estudio- surge principalmente en respuesta a la necesidad de políticas en torno al delito, la violencia y la inseguridad en la sociedad. La promoción del desarrollo humano y de las políticas sociales y públicas es la clave de los procesos de reforma y modernización de la gestión de los servicios y organismos públicos en los países de la región, y la policía es uno de ellos.

Es por esta razón que precisamos, por una parte, entender el funcionamiento de la policía - porque esto es clave para las políticas de prevención del deli- 
to y la violencia en una sociedad-, y - por la otra- ocuparnos también de la manera cómo se ejerce la función policial en la sociedad -cómo actúa la policía-, pues esto es decisivo para la estética de la democracia y de sus instituciones.

Así, nuestro objeto es tanto la organización policial como lo que ella es y hace. Aquí nos ocupamos de explorar la contribución de algunas disciplinas de las ciencias sociales a la generación de un mayor conocimiento y comprensión de ellas, sobre la base de conocimiento científico y estratégicas basadas en la evidencia, contribuyendo el desarrollo de la policía y de su misión en nuestros países.

\section{Consideraciones SObRe la Investigación de la Policía y Sus Desafíos}

El término policía designa una institución, una organización y grupo social abocado al control social formal. Sin embargo, es importante advertir que una cosa es la policía y otra, distinta, es la "actividad policial": la institución y la función son dos cosas diferentes, como señala Reiner $(2006,533)$.

¿Qué es una institución policial? y ¿̨cuál es la esencia de su función?. Un enfoque conceptual llevaría sólo a una definición más entre tantas otras igualmente legítimas o aceptables, destacando que la policía es una fuerza de seguridad sometida a las órdenes de las autoridades políticas, encargada de velar por el mantenimiento del orden y de la seguridad pública y ciudadana, que -ademáspresta una amplia gama de servicios la sociedad, teniendo un rol central en ella.

Un enfoque sistémico, por otro lado, enfatizaría las relaciones y sus manifestaciones con los componentes del sistema, más que sus atributos evidentes, y subrayaría su contribución, como parte de una compleja malla de interrelaciones funcionales a un propósito compartido: la coproducción de la seguridad y justicia en una sociedad.

Así, dentro de muchas posibles interrelaciones entre la sociedad, el Estado y la Policía, hay al menos dos que parecen esenciales y que deben subrayarse: la relación Sociedad-Policía y el vínculo Estado/Gobierno-Policía (Tudela 2007, 39-75). La policía es relevante tanto en sí misma como por su contribución al necesario capital simbólico que requiere todo Estado-Nación y, especialmente, el Estado de Derecho. 
El examen de la esencia de la función policial y su estrecha asociación con el contexto sociopolítico, a la luz de la evidencia en algunos casos latinoamericanos, permite afirmar que la reflexión sobre la función y la organización policial toman como marco de referencia diversas situaciones comunes entre varios países: i) la reforma y modernización del estado, i) el diseño y ejecución de políticas públicas de seguridad y iii) las consecuencias de éstos en los respectivos campos de desarrollo policial.

Esto es relevante, especialmente a la luz de las cifras que aportan encues$\operatorname{tas}^{1} \mathrm{e}$ informes ${ }^{2}$ que revelan en algunos casos enormes diferencias entre un país $\mathrm{y}$ otro y enormes tensiones entre la sociedad, la policía y el poder político.

Se pueden identificar tres tendencias generales, al menos, que explican procesos relevantes en los cuales se insertan policías y que hacen aún más necesario el desarrollo de la investigación sobre ella, en tanto organización y práctica:

a. Democratización: Cualquiera sea la modalidad de organización policial y sus estrategias preferidas, claramente la renovación de la misión policial en lo relativo a la visión y principios democráticos es una tendencia y un imperativo en las sociedad moderna.

b. Inquietud por las estrategias y la modernización: Hay mayor preocupación por la forma como se lleva a cabo la función policial. Los esfuerzos que buscan una mejora de la gestión en seguridad pública y ciudadana interpelan positivamente a las organizaciones de control social formal.

c. Control social: Hay mayor interés y desarrollo de nuevas modalidades de control y vigilancia sobre la actuación policial, a la par de una necesidad de validación de los mecanismos adecuados para asegurar la imputabilidad y la transparencia de las acciones policiales.

En consecuencia, los procesos descritos plantean retos a las policías e implican avanzar en el desarrollo y el fortalecimiento de ciertas capacida-

1 Para una visión panorámica de la región, recomendamos revisar los resultados de los estudios "Latin American Public Opinion Project" (LAPOP), de la Vanderbilt University, con una cobertura de 23 países de la región y 36 mil entrevistas; el Latinobarómetro, que es un estudio de opinión pública que aplica anualmente alrededor de 19 mil entrevistas en 18 países de América Latina; y, el Barómetro de Gobernabilidad, estudio que recoge la opinión de la población de América Latina, España y Portugal.

2 Organización de Estados Americanos, La Seguridad Pública en las Américas: retos y oportunidades, Washington, 2008, 91 pp. FLACSO-Chile, Reporte del Sector Seguridad de América Latina y el Caribe. Programa Seguridad y Ciudadanía. Santiago, 2007, 204 pp. 
des en las organizaciones policiales. Las policías enfrentan una mayor demanda de seguridad pública y servicios policiales, debiendo implementar una serie de innovaciones en materia de gestión con miras a alcanzar una mayor eficiencia y eficacia en sus resultados, alterando los parámetros de la evaluación de la respuesta policial. Hay, ciertamente, una transformación del paradigma de gestión, donde el producto esperado es más la seguridad que el control social (Herrera y Tudela, 2005, 5). Lo anterior se evidencia en cuatro dimensiones:

a) El diseño e implementación de nuevas estrategias de intervención;

b) La preocupación por la calidad de los servicios;

c) El interés por asegurar la eficacia de la acción policial en el marco de las políticas de seguridad pública y ciudadana y, consecuentemente, la capacidad de lograr el efecto que se desea o se espera en ambos casos; y,

d) El reposicionamiento de la legalidad y la legitimidad social como dos referentes fundamentales de una apropiada función policial, pues es ahí donde se consolida la función socio-política de una policía.

Estas tendencias, junto a otras, crean condiciones propicias para el desarrollo de un "buen gobierno" (gobernabilidad) y la "legitimidad social" de un "buen policiamiento", términos y temas comunes que se han vuelto relevantes en los últimos años. No hay duda que las policías enfrentan una transición y en ese tránsito las ciencias sociales pueden colaborar positivamente, de forma tal que el cambio necesario no represente una crisis y menos un trauma en la organización. La ciencia social aplicada es una oportunidad para la mejora continua en la policía.

\section{Estado del Arte de la Investigación sobre la Policía}

\subsection{Principales Temas le INTERÉS LE los INVESTigadores.}

La averiguación sobre la policía -como organización y praxis- da origen al encuentro de diversas disciplinas y genera un espacio común. Sin embargo, hay dificultades para la investigación sobre la policía y éstas no radican en las disciplinas, sino en la existencia de situaciones de diversa naturaleza. 
Ciertos factores y escenarios obstaculizan el estudio. Por ejemplo, la naturaleza diferente de las instituciones, la amplia gama de tareas y funciones que desarrollan, los diferentes tamaños, rasgos y estructuras de las organizaciones dificultan la comparación. Luego, a lo anterior se agrega la ausencia de fuentes de información, la escasa centralización de datos sobre la policía, el aislamiento de las organizaciones y el rechazo a informar, que hacen difícil el acceso a ella. Finalmente, la carencia de recursos para la financiación de investigaciones es también un componente fundamental. En pocos países se han desarrollado esfuerzos en esa dirección (Brasil y México). En definitiva, hoy no es posible formular aún apreciaciones contundentes y válidas, pues la evidencia empírica es todavía feble y escasa.

Todo ello contrasta con la importancia que posee la policía y revela una gran paradoja, pues existe la convicción extendida de que el desarrollo de políticas de prevención de la criminalidad y la violencia tiene como soporte principal a las policías, o bien la eficacia de esas políticas depende de mejoras en la actuación policial. No hay dudas de que los emprendimientos en busca de mejoras y cambios en pro de una mayor eficacia y calidad de los servicios policiales no sería posible sin antes conocer y entender qué es decisivo, cómo funcionan o, simplemente, por qué las estrategias policiales aplicadas en otras realidades funcionan allí pero no acá, por ejemplo.

Una mirada en detalle permite identificar ciertas temáticas de investigación, muchas de ellas desarrolladas de manera embrionaria por investigadores sociales en nuestra región, apoyándose fuertemente en pesquisas realizadas en países de tradición anglosajona. Las razones para ocuparse de la policía son variadas, pero entre ellas suele destacar la necesidad de cambio. En algunos casos, la actividad policial no es sólo un problema político, en el más amplio sentido de la expresión, es también parte del problema de la inseguridad y la justicia -en ocasiones hasta de impunidad. Problemas como malos procedimientos policiales, discriminación, irrespeto o violaciones de los derechos humanos y civiles, entre otros temas relevantes, marcan la agenda pública y dan pie a estudios sobre las policías.

Las materias estudiadas varían y ponen acento en diversas facetas del quehacer policial, primando un enfoque microsocial, sumado a la preocupación por factores situacionales y la relación entre algunas variables particulares. A continuación se señalan algunos ejemplos, clasificación que -por cierto- $\mathrm{n}$ es exhaustiva y que sólo pretende destacar algunos de los contenidos abordados en las publicaciones e investigaciones: 
1. El papel de la policía como órgano de control social y la política (Rico y Salas 1988, Sain 2002, 2008, Sozzo 2005);

2. La organización (Sain 2008);

3. La clase social y el género (Martín 1994, GTZ-Nicaragua 2005, Rodrigues 2007, PDI 2009);

4. Los procesos de reforma (Frühling 2009);

5. Las condiciones de trabajo (Azaola 2008);

6. La conducta desviada, abuso y la discrecionalidad policial (Schmid 2007, Arias y Zuñiga 2008, Rodríguez, 2008);

7. Los derechos humanos en la policía (Izquierdo 2002, Candina y Lünecke 2004, Muniz 2006);

8. La relación con el desarrollo democrático (Rico y Chinchilla 2006, Kaminsky 2005);

9. Las relaciones con la comunidad y las estrategias policiales orientadas a la comunidad (Frühling 2004, Tudela 2008);

10. La decisión de ser policía y la formación (Sirimanco 2004);

11. La socialización, carrera policial y la profesionalización (Kant de Lima 2004, Dias 2002);

12. Las prácticas policiales e identidad (Muniz 1999, Souza 2001, Oliveira 2002, Sirimarco 2004, Oliveira Junior 2007);

13. Las representaciones sociales en la policía (Ramos y Musumeci 2005, Hagen 2005);

14. Las opiniones y percepciones en y de la policía (Oliveira Junior2007), entre otras.

Un breve análisis de diversas publicaciones permitiría concluir cuatro cosas:

- Primero, que en América Latina -de acuerdo a la evidencia acumulada relativa a la última década- las investigaciones sobre una organización y su actividad, inevitablemente producen resultados de alcance y universalidad limitados.

Esta es una conclusión que no debe sorprendernos, pues ya lo destacaba Murphy (2005) en sus comentarios de los resultados de la conferencia de 
Kentucky (2003) y que explora las principales inquietudes de los investigadores de la policía en Estados Unidos. Él subraya que las investigaciones se basaban esencialmente en realidades locales, anglo-americanas y vinculadas a materias de quehacer policial, tales como género, raza, uso de la fuerza, tecnología, estrategias de dirección, desarrollo del debate sobre la orientación comunitaria, es decir, materias policiales importantes en contextos sociales e institucionales de países desarrollados, pero ellas no son temáticas universales.

- Segundo, la organización y la actividad o praxis policial son asumidas como dos campos de investigación relacionados, cada uno con problemas-temáticas y desafíos teórico-prácticos propios. Pero, ésta tiene un fuerte acento en los intereses que rodean a la policía, más que los de las organizaciones, en decir, no es totalmente evidente que los intereses de la policía se reflejen en dichas materias. Los investigadores de la policía están generalmente fuera de ella. A esto se agrega que lo que se investiga no necesariamente coincide con otros estudios. Es necesario, entonces, definir una agenda de exploración común, tópicos de interés compartidos para aunar esfuerzos y facilitar el aprendizaje colectivo.

- Tercero, que las investigaciones realizadas a la fecha no se enmarcan en un proceso de pesquisa sistemática y, menos aún, puede referirse un cúmulo de conocimientos o teorías particulares que permitan arribar a generalizaciones, o bien desarrollar un enfoque holístico sobre la policía, en especial en nuestra región. Las monografías de casos son poco frecuentes y la comparación no es posible, a pesar de algunos esfuerzos de naturaleza jurídica (Ambos et al 2003).

- Cuarto, que -a la luz de los desafíos que enfrentan las policías en materia de modernización y control externo- la investigación sobre la organización y la praxis policial se relacionan y conviven con la necesidad de estudiar y reflexionar acerca de los modelos de gestión que promueven consecuentemente la eficiencia, la eficacia y la calidad de servicio policial y la orientación al ciudadano o usuarios.

Se trata, entonces, de un punto de encuentro que genera una ventana de oportunidades entre la organización policial y las ciencias sociales: los análisis pueden contribuir significativamente al propósito de recrear la misión de la policía en la sociedad, acompañando ese tránsito desde el control social a la producción de seguridad, escenario que vive la mayoría de las organizaciones policiales en nuestra región. 


\subsection{Enfoques Disciplinarios y Aportes Fundamentales.}

Sin duda, dada la naturaleza de la policía, ella concita un amplio espectro de intereses y posibles facetas de estudio, transformándose en un campo y objeto donde la interdisciplinariedad se vuelve necesaria, en tanto estrategia investigativa más fructífera, pues ayuda a explorar y comprender una realidad multifacética y polivalente como es la función y la organización policial. Tanto la policía como los policías y su lugar social-cultural han sido el centro de la indagación de las ciencias sociales.

Tres paradigmas determinan el modelo a seguir en la exploración científica y social: El paradigma lógico-positivista o empírico-analítico y/o cuantitativo, el paradigma simbólico-interpretativo-cualitativo y, finalmente, el paradigma crítico o dialéctico. Los dos primeros son más frecuentes y tienen en común que el investigador se aproxima a la realidad privilegiando la neutralidad. No se investigar la realidad para emanciparla, a diferencia del último.

En la práctica, los paradigmas se diferencian en que reflejan posturas fundamentales y distintas sobre la naturaleza del conocimiento y la realidad que buscan (empírica, objetiva, material o no), la relación entre el investigador y el conocimiento que privilegian (personal o impersonal), el modo de construir el conocimiento en la investigación (descubierto o construido) y el propósito de la indagación (explicación o comprensión).

En ciencia social los paradigmas no son propiedad de una disciplina. En cada una hay uno u otro paradigma característicos o uno que es más recurrente. En ocasiones son los investigadores, mientras que en otras son las materias de interés y ciertas facetas del objeto lo que lleva a uno u otro. Ciertamente, ni los enfoques ni los estudios de policía son estrictamente disciplinarios. No hay una delimitación clara.

A menudo, en el contexto de la investigación social las disciplinas son portadoras de una identidad teórico-metodológica que se construye sobre la base de una definición de un campo y un objeto característico, destacando un sello particular. Sociólogos, psicólogos sociales y antropólogos miran la realidad desde puntos de vista distintos. Estas miradas no son, por cierto, excluyentes ni exclusivas, tampoco los métodos y sus técnicas. Se trata de énfasis diferentes a la hora de buscar o relevar causas y factores determinantes: a veces es más importante la institución, en ocasiones la interacción de los individuos con los grupos, en otras es la cultura. 
A continuación se revisa -de manera sintética- algunos aportes de cada disciplina, destacando la perspectiva que los caracteriza y, luego, nos concentramos en la perspectiva cultural.

\subsubsection{Sociología (DE la policía).}

La sociología surge en la sociedad occidental ocupándose de las instituciones modernas. Ella se dedica al estudio de la sociedad y su estructura, de la acción social y de los grupos que la conforman, y de cómo las organizaciones y las instituciones son creadas, mantenidas o cambiadas, y relacionan éstos con la interacción social y otros procesos de mayor envergadura y complejidad (macrosocial) .

La investigación sociológica subraya cómo la estructura y funcionamiento de una policía se encuentran entrelazados complejamente con diversos procesos sociales y revela, por ejemplo, que la institución de hoy vive una tensión entre autonomía y subordinación-dependencia en el ejercicio de su mandato. En general, el campo de exploración se concentra en la interrelación de la institución con otros focos y estructuras de poder en la sociedad, asimismo con el ciudadano.

La pesquisa sociológica sobre la policía tomó fuerza en Inglaterra y Estados Unidos en la década de los sesenta. En el contexto anglosajón se ocupó de describir las pautas de procedimientos policiales, las fuentes de desviación y las reformas necesarias, centrándose en el papel de la organización, en la personalidad del policía y en la socialización del policía (Reiner 2006, 528).

En este campo destacan los enfoques que se focalizan en la policía como un rasgo distintivo del Estado moderno "no a modo de representación, sino como aparición paradigmática” (Galeano 2008, 103), la relación con la sociedad y, al mismo tiempo, la explicación de su comportamiento a partir de su modelo organizativo y del entorno en que trabaja. Esta perspectiva fue empleada por Diego Torrente (1997) en el caso de una policía de Cataluña, donde también subrayaba cómo la cultura y la percepción de riesgo, la autoridad y la racionalidad son elementos organizacionales claves que explican las respuestas policiales. Enfoque similar emplean Dellasoppa (2001) en su averiguación sobre la policía civil en Rio de Janeiro y Beato y Marinho (2006) en el caso de las policías militares de Belo Horizonte, Rio de Janeiro y Vitória en Brasil. 
Según Sozzo (2005, 9), los estudios sociológicos en América Latina se encuentran en la infancia, recurriendo a la literatura producida en Estados Unidos, Gran Bretaña y Canadá. Con frecuencia se enfocan en lo que "la policía hace", en el diseño e implementación de políticas policiales, en el deber ser de la actuación policial, su evaluación y su eficacia Algunos trabajos se han referido al uso de la fuerza policial, especialmente en Brasil y Venezuela. Otros se orientan al funcionamiento de los mecanismos de control de la actividad policial, por ejemplo, en Chile (Tudela 2005) y Colombia. Un tercer grupo de investigaciones -el más recurrente- se aboca a las reformas policiales y las experiencias de "policía comunitaria" en Perú (Diez 2004), Brasil (Oliveira 2007); Colombia, Guatemala, Nicaragua, entre otros ${ }^{3}$.

\subsubsection{Psicología Social.}

Este dominio interdisciplinario salva el espacio entre la psicología y la sociología y se orienta a la comprensión de la conducta social, sobre la base de estudiar los procesos de influencia social. En otras palabras, estudia cómo los pensamientos, sentimientos y comportamientos de las personas son influenciados por la presencia real, imaginada o implicada, de otras personas o grupos. $\mathrm{Su}$ sello distintivo emerge, entonces, de dos factores fundamentales. Por un lado, el interés en el individuo como participante social y, por el otro, la importancia que recibe la comprensión de los procesos sociales. En rigor, se encarga de explicar un amplio espectro de hechos sociales: la percepción social, los prejuicios, las tensiones entre grupos, los comportamiento no verbales, entre otros.

Esta disciplina asume como supuesto la existencia independiente y observable de procesos psicológicos sociales de diferente orden al de los procesos psicológicos del individuo, pero de la misma naturaleza. Típicamente, los psicólogos sociales explican el comportamiento humano como resultado de la interacción de estados mentales y situaciones sociales inmediatas.

Desde esta perspectiva, la policía es vista como organizaciones configuradas en torno a los aspectos socioculturales, derivados de la interacción de

3 Esta materia ha sido analizada en detalle en "Reforma y modelos de gestión policial orientados a la comunidad: aplicabilidad de los modelos Community Oriented Policing (COP) y Problem Oriented Policing (POP) en Chile". Tesis del Master en Gestión y Dirección de la Seguridad, Universidad Autónoma de Barcelona, 2007. Parte de ella ha sido publicada en: TUDELA, Patricio; Paradigmas policiales orientados a la comunidad en América Latina: entre realismo mágico y gestión de conocimiento. En: Revista Estudios Policiales, Santiago, No 3, Diciembre de 2008, pp. 11 -34. 
individuos. Este enfoque es muy útil al estudiar facetas relevantes del trabajo policial: la conformidad, el liderazgo, el clima laboral, actitudes positivas o negativas frente a otros y frente a actividades vinculadas al trabajo, el estrés del policía y el conflicto intergrupal. En esto un ejemplo valioso es la indagación realizada en Carabineros de Chile (Briones 2007) y que representa uno de los primeros esfuerzos en replicar estudios realizados en Estados Unidos y Australia ${ }^{4}$.

A través del acercamiento a las representaciones y prácticas propias del mundo policial, que conducen a la producción y la reproducción de las visiones internas dominantes, es posible traducir y esclarecer las distintas lógicas y las tensiones entre ellas y con el mundo no policial.

Desde la psicología social, Wilson (1968) identificó tres estilos policiales, que denominó como "vigilante", "legalista" y "de servicio". Si bien estas categorizaciones son fruto de observaciones en ocho fuerzas de policía en Estados Unidos (National Research Council 2004, 131 y 132; Reiner 2006, 552).

Investigaciones recientes, destacan la existencia de perfiles profesionales que se pueden diferenciar según su disposición a ciertos elementos propios de su campo laboral o de desempeño: i) su inclinación o distancia frente al ciudadano, ii) la tolerancia a la supervisión, iii) el apego a las directrices de actuación, iv) su actitud hacia la aplicación de la ley, v) su disposición a la mantención del orden, vi) la visión sobre el trabajo policial orientado a la comunidad, vii) la agresividad o uso de la violencia, viii) la selectividad o discriminación en el ejercicio de la función policial (Paoline, 2001; Paoline, 2004). Hasta la fecha, esta es una materia no suficientemente explorada en las policías de nuestra región y menos conocemos el impacto de esto en las estrategias policiales de prevención y control del crimen y de relacionamiento con la comunidad y los gobiernos locales.

En este campo, sin embargo, la investigación sobre la policía toma del constructivismo ${ }^{5}$ dos términos relevantes: representaciones sociales y habitus. Ambos sirven para reconocer a los individuos dentro de las organizaciones, cómo desarrollan un campo intersubjetivo y las estrategias de adaptación

4 Mayhew C.; Occupational health and safety Risks Faced by Police Officers. En: Journal of Australian Institute of Criminology. 2001, No 196, pp. 1-6.

5 El constructivismo afirma que una persona, tanto en los aspectos cognitivos, sociales y afectivos del comportamiento, no es un mero producto del ambiente ni un simple resultado de sus disposiciones internas, sino una construcción propia que se va produciendo día a día como resultado de la interacción de estos dos factores. 
cognitivas a las reglas institucionales, cómo rediseñan las prácticas cotidianas compartidas y cómo razonan, o lógicas que emplean y que no siempre coinciden con los objetivos declarados de la institución.

En el primer caso, las representaciones sociales, todos poseen y aprenden sistemas cognitivos y esquemas interpretativos de la realidad que los rodea. Así, cuando las personas hacen referencia a algún objeto-situación social (la policía, la comunidad, el uso de la fuerza, etc.), los clasifican, explican y evalúan porque tienen una representación social o imagen de ese objeto-situación. La "realidad" es una construcción social y todos participan en la construcción de ese imaginario. Cada organización posee uno o varios imaginarios y cada individuo está inserto en ellos.

En rigor los policías poseen representaciones sociales o imágenes de todos los componentes (actores, objetos o elementos) que integran su ser/hacer policial. Pero, al tratarse de una construcción colectiva los contenidos no son homogéneos. Aquí es cuando el término habitus es clave para entender las dinámicas de la diversidad y la heterogeneidad al interior de la sociedad y las organizaciones policiales. Todos los grupos e individuos poseen códigos, valores, lógicas clasificatorias, principios interpretativos y orientadores de las prácticas, que se expresan en estereotipos, opiniones, creencias, valores y normas que suelen tener una orientación actitudinal positiva o negativa que rigen o influyen con fuerza normativa, en tanto instituye los límites y las posibilidades de la forma en que actúan los miembros de una organización y la sociedad (Araya 2002,11; Oliveira 2007, 13).

Por habitus se entiende el conjunto de esquemas de obrar, pensar y sentir asociados a la posición social. Estos esquemas generativos están socialmente estructurados: han sido conformados a lo largo de la historia de cada sujeto y suponen la interiorización de la estructura social, del campo concreto de relaciones sociales en el que el individuo social se ha conformado. Pero, al mismo tiempo, son estructurantes: son estructuras a partir de las cuales se producen los pensamientos, percepciones y acciones de la gente.

A cada posición social distinta le corresponden distintos universos de experiencias, ámbitos de prácticas, categorías de percepción y apreciación. Cada posición social tiene su propio habitus, creándose así un marco de cada 
posición social ${ }^{6}$. El habitus hace que personas de un entorno social homogéneo tiendan a compartir estilos de vida parecidos.

En las pesquisas de la policía el habitus ha ganado relevancia, en la medida que se ha vuelto un principio explicativo de la generación y estructuración de prácticas y representaciones, y define los comportamientos considerados positivos por el grupo, el lugar de cada individuo dentro de la organización y hasta dónde éste puede llegar en la carrera, ajustando las expectativas personales a las posibilidades objetivas, como lo destaca Hagen (2005) en tesis doctoral en psicología sobre la Policía Militar del Estado de Rio Grande do Sul en Brasil.

Siguiendo a la autora, el ambiente en que se desenvuelve el trabajo policial (delegaciones, cuartes, espacios públicos, etc.) no es el factor determinante para la diseminación de los valores y comportamientos compartidos por los policías, sino la cadena de experiencias desde el ambiente familiar hasta las experiencias en el mundo del trabajo. El individuo que ingresa a la profesión de policía porta su propio habitus. Este debe ser suficientemente maleable y compatible -transformado y ajustado- a los habitus diseminados por la institución en la cual se inserta. Cada miembro de la organización se envuelve en una red heterogénea que explica la fragmentación y la diferencia. De esta forma, en todas las instituciones hay habitus y son la clave analítica de la evaluación de los comportamientos concordantes con los valores dominantes diseminados, creando a partir de ahí jerarquías y clasificaciones (Hagen 2005, 80).

Habitus y representaciones sociales son dos términos que ayudan a comprender las actitudes y prácticas policiales positivas y negativas, la estigmatización y las etiquetas. Pero, también sirven para comprender la existencia de rasgos propios de la conducta y las actitudes del policía, como la distancia y la sospecha o desconfianza en relación a quienes no son policías.

\subsubsection{Antropología (DE una policía).}

La antropología surge como posibilidad científica de comprender y analizar los modos de vida de sociedades diferentes. Postula que gran parte de la

6 Con la introducción del concepto de habitus, Pierre Bourdieu busca explicar el proceso por el cual lo social se interioriza en los individuos para dar cuenta de las "concordancias" entre lo subjetivo y las estructuras objetivas Para él, la visión que cada persona tiene de la realidad social se deriva de su posición en este espacio. Las preferencias culturales no operan en un vacío social, dependen de los límites impuestos por las determinaciones objetivas. Por ello, la representación de la realidad y las prácticas de las personas son también, y sobre todo, una empresa colectiva. Bourdieu, Pierre; Cosas dichas. Editorial Gedisa, Buenos Aires, 1988. 
conducta humana es social y es aprendida, es decir, es cultura, y que ésta es una malla de significados, una realidad envolvente y dinámica. Aún cuando estudia "la cultura", el antropólogo no admite la existencia de una realidad única, porque asume que existe una diversidad de "culturas". Se ocupa básicamente "del otro" (alteridad) y reconoce la diferencia y la diversidad: la "otredad cultural"7. El objeto de la antropología es en un comienzo el estudio de pueblos y culturas no occidentales (comunidades indígenas, sociedades primitivas, etc) lo que se denominó como "el otro cultural".

- El interés inicial de la Antropología es el estudio de aquellas culturas que han crecido sin una tradición de escritura

Privilegia un enfoque cualitativo ${ }^{8} \mathrm{y}$, más que descripciones que busquen la explicación (erklären) fáctico-descriptiva de los acontecimientos que observa, promueve la comprensión (verstehen) y "la interpretación densa" de circunstancias sociales con alto contenido simbólico-cultural (según C. Geertz). Desde esta perspectiva, la intersubjetividad es un instrumento para conocer las realidades humanas y no un obstáculo para el desarrollo del conocimiento.

La pesquisa antropológica sobre la policía toma fuerza en aquellos países donde la explicación sociológica no parece suficiente para comprender procesos que no se explican por situaciones "anexas o externas al individuo", sino por factores más subjetivos y que subyacen en esas realidades. En América Latina se desarrolla al amparo de algunas universidades y centros de estudios, especialmente en México, Brasil, Perú, Argentina, Chile? . La exploración asume un enfoque sociocultural, priorizando la indagación de los policías desde adentro - desde la propia organización-, ya que es ésta la que le da sentido a su ser/quebacer-.

7 Los antropólogos solemos hablar de "relativismo cultural", lo cual significa que cada cultura tiene valor en sí misma y que no hay culturas ni sociedades superiores o inferiores. El relativismo enuncia que todos los juicios de valor son relativos a la cultura de referencia. En efecto, el significado es relativo al contexto del significante.

8 Desde esta perspectiva, los estudios se fundamentan en enfoque micro y en la búsqueda de significados contextuales y suelen basarse en fuentes que difícilmente reproducen aquella representatividad y validez exigida a la hora de explicar -sobre la base de la evidencia- situaciones que se observan en distintos momentos y realidades. Se trata de observaciones que buscan comprender, más que explicar, y que buscan reconocer el juego de subjetividades y particularidades (enfoque cualitativo).

9 Precisamente en aquellos lugares donde la antropología hace de los problemas sociales, de los problemas urbanos, de las dificultades de políticas de desarrollo, entre otras materias, su campo privilegiado, reemplazando al nativo. La comparación intercultural y la interculturalidad se lleva "a casa" y "al cuartel de policía”. 
Los antropólogos aportan al menos tres nociones básicas a la investigación de la policía. Por una parte, reconocen con más facilidad el etnocentrismo que naturalmente envuelve la mayor parte de los juicios interpretaciones y explicaciones que puedan darse sobre una realidad particular, haciendo evidente la inquietud por quién habla o afirma algo y desde qué lugar lo hace. Por la otra, desarrollan una visión holística, es decir, una visión del todo e integradora, capaz de concebir la realidad estudiada como compuesta de partes o variables -reales o conceptuales- completamente interdependientes unas de otras ${ }^{10}$; y, finalmente, aportan simultáneamente una visión emic y etic ${ }^{11}$ (desde dentro y desde fuera) de las organizaciones y los actores. En rigor, el virtuosismo del antropólogo está dado por su capacidad de penetrar en el punto de vista de los observados (enfoque emic), es decir, en conocer la vida por dentro, las ideas, sentimientos y representaciones colectivas:

"La antropología es el estudio del hombre en sociedad. Consiste en un
ejercicio de ponerse en los zapatos del otro, situarse en su perspectiva
para ver cómo ve el mundo. Ver a la policía desde un punto de vista
antropológico implica tratar de entender los problemas cotidianos de
los policías y la realidad en la que viven. Más allá de establecer a la
policía como objeto de estudio, este enfoque busca mirar al otro, verse
en el otro y propiciar el aprendizaje mutuo para, mediante el diálogo,
lograr un enriquecimiento compartido" (Azaola 2006, 9)

Los trabajos sobre policías, desde la perspectiva de la antropología social y la etnografía, tienen mayor data en Brasil y Argentina (Sirimarco 2009), concentrándose -por ejemplo- en policías civiles y militares en los Estados de Rio de Janeiro (Muniz 1999), Sao Paulo (Oliveira 2002, Izquierdo 2002) y Belo Horizonte (Souza 2001); con posterioridad se inician averiguaciones en México (Azaola 2006; Suarez de Garay 2002 y 2006) otros países (Tudela 2004). La práctica investigativa es en pequeña escala y, a veces, con una visión crítica. Se recurre con frecuencia a la observación, al estudio de casos, a la entrevista, al análisis de documentos y, en ocasiones, al empleo de encuestas.

10 En ese sentido, la explicación de un fenómeno cultural o social no es inherente al hecho en sí, si no a las relaciones que tiene con otros elementos del sistema. La noción del antropólogo como traductor se ha ido transformando hacia la del antropólogo que interpreta y hace juegos de representación, o la de "observador/constructor/actor.

11 Los enunciados emic se refieren a distinciones del actor cultural y describen los sistemas sociales de pensamiento y de comportamiento cuyas distinciones, entidades o hechos están constituidos por categorizaciones, contrastes y distinciones percibidos por los propios participantes como reales, representativos, diferentes o apropiados. El estudio y reconstrucción desde esta perspectiva exige que se entre en el mundo de los propósitos, los sentidos y las actitudes desde los actores. Los enunciados etic, por su parte, dependen de las distinciones consideradas apropiadas por una comunidad de observadores científicos - generalmente desde la teoría y el paradigma que se emplea. 
Las pocas publicaciones coinciden en aclarar la complejidad del mundo policial y ayudan a vislumbrar algunas situaciones socioculturales que posibilitan la reproducción de la policía como organización y práctica natural y cotidiana, como nos muestra el estudio de Barros en Minas Gerais-Brasil (2005). Para ello, se recurre a la cultura como principal objeto y factor determinante.

Algunas etnografías destacan, por ejemplo, una tensión entre los marcos constructivos del orden social y el margen de indeterminación de los sujetos sociales, invitando a sumergirse en los procesos de significación y acción y comprender las prácticas culturales que se dan dentro de un sistema determinado (Suarez de Garay 2001). Las investigaciones demuestran que no siempre hay un isomorfismo entre pensar-hacer y decir y que hay un contexto social y cultural significante en el ser/hacer policía.

En síntesis, las ciencias sociales, en especial la antropología, aportan un conjunto de herramientas teóricas, conceptuales y prácticas que ayudan a dilucidar y esclarecer diversas facetas del acontecer policial.

\subsection{HACIA LA CONSTRUCCIÓN DE UNA SÍNTESIS Y PERSPECTIVA COMPARTIDA.}

La revisión de la investigación sobre la policía y los enfoques que suelen caracterizar las disciplinas ayudan a construir una perspectiva de análisis desde la cual proponemos observar y estudiar lo que la policía es y hace, la organización y la praxis policial. Compartir esto ayudaría al diálogo interdisciplinario y a materializar una mejor contribución de las ciencias sociales, en especial la antropología, a la institución policial y su labor.

El primero es comprender que la actividad y la función policial tienen una base social, que son una realidad multifactorial y que asoman diversas dimensiones: Es fundamental ver la policía como función de Estado, como poder, como organismo, como servicio, como persona, como forma de vida, entre otras. En consecuencia, una policía es una organización y, a la vez, una práctica. Es siempre un producto particular, fruto de la convergencia de una institucionalidad, de un estilo de hacer, de una visión de mundo y de un entorno desafiante. Esta respuesta es una construcción social y cultural.

La indagación social empírica es la forma de responder ordenada y sistemáticamente a un conjunto de preguntas sobre esa realidad. La investi- 
gación sobre la policía es, de manera indiscutida, un campo que presentan diversos desafíos teóricos y prácticos en el ciclo de pesquisa, atendida la naturaleza del objeto y de las unidades de análisis. De esta forma, la sociología, la antropología y la psicología social son herramientas disciplinarias de enorme utilidad al desarrollo policial.

El segundo es que la policía no puede verse como algo externo a la sociedad, sino como algo imbricado en ella, de la cual forma parte y que, en mayor o menor medida, refleja. Egon Bittner, uno de los primeros sociólogos norteamericanos en ocuparse de la policía, señaló alguna vez que la sociedad representa a la policía y que ésta trabaja para servir a la sociedad y que su papel es tratar todos los tipos de problemas humanos en los que la solución necesite o pueda necesitar del empleo de la fuerza (Bittner, 1990, 226 y 230; citado por Sozzo, 2005, 12).

El tercero se ampara en el constructivismo o interaccionismo simbólico, que nos lleva a pensar que la comunicación e interrelación de personas y grupos es clave en la construcción y producción social de sentido y que las personas actúan sobre los objetos de su mundo e interactúan con otras personas a partir de significados compartidos y generados colectivamente.

De acuerdo a esto, los miembros de una organización policial participan en procesos interpretativos, es decir, seleccionan, organizan, reproducen y transforman los significados en función de sus expectativas y propósitos. Así, signos, símbolos y significados son indicadores sociales que interviene en la construcción de sentido en la organización y lo mismo ocurre en materia de praxis policial. De esta manera, el imaginario social que circula sobre la policía, también es consumido, reconocido y construido por ellos mismos, e influye significativamente en sus propias maneras de ser/hacer. Esto incide en sobre las estrategias y actuaciones policiales ${ }^{12}$.

El cuarto supuesto es que asumimos que el conocimiento es una creación compartida a partir de la interacción entre el investigador y el investigado. En ellas los valores median o influyen la generación del conocimiento; lo que hace necesario "sumergirse en la realidad" que refleja nuestro objeto, para poder comprenderla tanto en su lógica interna como en su especificidad. Así, el esce-

12 Kant de Lima, Roberto; Policía, justicia y sociedad en el Brasil: un abordaje comparativo de los modelos de administración de conflictos en el espacio público. En: Derechos Humanos, tribunales y policía en Argentina y Brasil. Estudios de antropología jurídica. Sofía Tiscornia y María Pita (Edit.), Buenos Aires. Facultad Filosofía y Letras (ICA) UBA / Antropofagia, 2005. 
nario propio y natural para conocer la policía es la práctica cotidiana y pasos claves son el análisis inductivo y la investigación emergente. En rigor, asumir la pesquisa desde la perspectiva de los actores y protagonistas de los procesos que estudiamos es "un valor agregado" para el conocimiento de la policía.

Suárez de Garay (2001), antropóloga abocada a estudios de policía en México, señala en una de sus investigaciones que la conclusión más importante que arrojaron los datos trabajados al estudiar la policía de Zona Metropolitana de Guadalajara fue que los personajes y acciones que integran una de las instituciones esenciales del Estado, la policía, son un reflejo concreto de la dinámica social en México ${ }^{13}$. En consecuencia, el mundo policial es una cultura que tiene su propia lógica y que para poder entenderlo, hay que analizar a la actividad y la organización desde aquellos que la conforma: los policías.

Un quinto supuesto dice relación con la interdisciplinariedad, como práctica y estrategia investigativa más apropiada, dada la naturaleza psicosocial y cultural del objeto: la policía como organización y como praxis. Esto se refiere a la necesidad de desarrollar un tipo de trabajo científico que requiere la colaboración de diversas disciplinas y, en general, la cooperación de especialistas de distintas áreas, para alcanzar una visión y comprensión holística.

Más allá de la identidad y propósitos de cada disciplina, el conocimiento acumulado, los distintos paradigmas ${ }^{14}$ y enfoques y el perfeccionamiento de las técnicas de recolección y análisis de la conducta humana se potencian aún más cuando se ordenan en función de una estrategia interdisciplinaria sobre un fenómeno que -como la pobreza y el desarrollo, por ejemplo- no se reducen a una disciplina.

En el caso de Iberoamérica, esta perspectiva quedó bien plasmada hace casi dos décadas en uno de los primeros estudios sistemáticos sobre la policía en España. Realizado por Manuel Martín (1990), la investigación se basa en aproximarse a la organización con un enfoque que hasta hoy no deja de mostrar su validez al mirar, con una visión holística, la policía como una organización compleja (enfoque histórico), la actividad policial como una profesión (análisis sociológico y psicológico) y, asimismo, como parte de un sistema de control social.

13 Suárez de Garay, Maria Eugenia; ¿Captas cómo está el trasfondo? Esbozo para un acercamiento antropológico a la policía tapatía. Athenea Digital Test, abril 2001.

$14 \mathrm{Me}$ refiero el cuerpo de creencias, presupuestos, reglas y procedimientos que definen como hay que hacer ciencia, en otras palabras, son los modelos de acción para la búsqueda y generación del conocimiento. 


\subsection{Perspectivas de Estudio sobre la Policía y lo Policial}

Las ciencias sociales son disciplinas que se ocupan de aspectos del comportamiento humano y sus actividades. Ellas examinan tanto las manifestaciones materiales como las inmateriales de las sociedades, instituciones, organizaciones e individuos. Las ciencias sociales, en su estado actual, no pueden establecer leyes de alcance universal sobre la conducta humana. Más aún, algunas -como la antropología- no pretenden aquello, por lo que muchas veces el objetivo es simplemente describir, explicar o interpretar -según sea el paradigma que se emplee-, prever o predecir y, finalmente, actuar o controlar los hechos y conductas, si se quiere avanzar en el uso del conocimiento, interviniendo o intentando modificar la realidad observada.

La transición en cada una de las etapas descritas más arriba se basa en el empleo de un soporte fundamental: la condición de que el conocimiento adquirido y la reflexión propia se sujeten a procedimientos consensuados por la comunidad científica (actuaciones estandarizadas sujetas a repetición y revisión) que aseguran su validez y "objetividad", dentro de lo posible. Esta no es una condición únicamente instrumental, sino también -y hasta cierto punto- moral, por cuanto se trata de producir un conocimiento que será empleado en función de problemáticas sociales relevantes y decisivas para el desarrollo humano, social y político en nuestros países. Hay, sin duda, una responsabilidad ineludible.

El "esclarecimiento" y la pesquisa sobre la realidad policial es instrumental a un propósito, cual es, alcanzar mayores niveles de eficacia y calidad de los servicios policiales en pro de políticas criminales y de seguridad más pertinentes. Nadie puede negar que en los últimos años, en la mayoría de los países de la región existe una importante apuesta por desarrollar políticas más eficaces y costo eficientes. La convicción de que la calidad de las intervenciones juega un papel fundamental en los productos, resultados e impactos de la respuesta u oferta pública de los servicios de seguridad e investigación criminal, lleva a poner atención en qué está haciendo la policía, cómo y con qué logros ${ }^{15}$.

15 Necesitamos "estudiar" el comportamiento de las distintas variables que convergen en la inseguridad, pero también la actuación de las instituciones para comprender por qué un suceso o conjunto de sucesos criminales se dan, se mantienen, aumentan o disminuyen. 
De esta forma, las ciencias sociales ${ }^{16}$ representan el conjunto de disciplinas que potencialmente convergen en auxilio de la indagación sobre la organización y la actividad policial, con el propósito de describir, explicar e interpretar los hechos que les son propios, reales y potenciales, objetivos y subjetivos, por medio de paradigmas, enfoques teórico-conceptuales y herramientas características. El principal aporte radica, entonces, en que pueden proporcionar a la sociedad y sus autoridades una compresión mas precisa de tales hechos. En la actualidad hay buenas razones que alimentan la convicción y un sentido de urgencia de que es necesario incursionar en estudios sobre la policía desde "adentro":

"Necesitamos comprender de qué está hecha la policia. En este sentido, la antropología, como ciencia comprensiva y general, que estudia el presente de cualquier cultura, puede hacer aportaciones significativas en esta tarea" (Suárez de Garay 2006, 4)

En distintos países es posible observar que -al amparo del desarrollo de políticas criminales y de seguridad pública y ciudadana- las instituciones policiales inician la generación de dinámicas de servicio más participativas (coproducción), promueven actitudes y conductas más aptas para conseguir los objetivos y metas, impulsan formas de entender el papel de cada uno en la organización, sus valores, su doctrina y su ética, buscan garantizar la calidad de los procedimientos con el máximo de transparencia y procuran o intentan gestionan el cambio continuo.

En la actualidad, es común que se hable de cambios en la "cultura de la policía" -generalmente al amparo de procesos de modernización o reforma- aspirando a que, por ejemplo, las estrategias y actuaciones concuerden con los preceptos de una policía democrática. Asimismo, pocos ponen en duda que la gestión policial, el ejercicio del mando y las conductas de los policías pueden ser y en realidad son más decisivos que lo en alguna época que se pensó. La cultura puede tener repercusiones importantes en los resultados y en la forma de hacer/ser policía. Ella es incluso más relevante cuando algunas expectativas internas y externas no se cumplen.

Esto lleva la necesidad de ocuparse de desarrollar nociones, conocimientos, medios, competencias, etc. para remediar problemas, para corregir y

16 En rigor, el estudio de las instituciones policiales a través de un enfoque jurídico no es suficiente para comprender las complejidades de la actividad policial. Entender la policía como aparato del Estado destaca sólo aspectos formales de la institución, como si la norma legal fuese una realidad en si misma suficiente y, a su vez, una práctica social verdadera, materia que la propia observación cotidiana se encarga de demostrar que no es así. 
para facilitar un aprendizaje colectivo (organizacional). Así, es preciso investigar para conocer y cambiar, es decir, para explicar y desarrollar estrategias de solución. Nada de lo anterior es posible si no se aborda la organización policial como cultura. En rigor, para poder entender los procesos internos de una organización policial, debemos estudiar y conocer la cultura organizacional en ella. En otras palabras, es útil conocer el modo de ser de la organización.

En consecuencia, estimamos como muy probable que la cultura de la policía sea en los próximos años un factor cada vez más relevante y que así lo entiendan los líderes de las organizaciones, y quienes toman decisiones y ejecutan políticas de seguridad pública y ciudadana.

\section{La Policía como Cultura Organizacional y Praxis Cotidiana.}

\subsection{La Cultura es lo Que Importa.}

La investigación sobre la policía (Chan 1997; Torrente 1997; Paolina 2001 y 2004; Manning 2005; Zhao y Hassell 2005) y la antropología -especialmente la que se ocupa de las organizaciones- enseñan que a la hora de comprender los hechos y concebir lo que es posible -en términos de cambio y desarrollo organizacional-, la cultura es una variable relevante e "independiente". La experiencia personal en una organización de policía -la Policía de Investigaciones de Chile- y las investigaciones realizadas por Acha (2004) en Perú, Bretas y Poncioni (1999) en la policía civil de Río de Janeiro, Oliveira (2007) en la Policía Militar de Minas Gerais, entre otros estudios, confirman lo señalado.

Desde las primeras definiciones de cultura a fines del siglo XIX, que destacaba una aproximación positivista, pasando por una aproximación adaptativa-funcionalista, una subjetiva-ideacional y una aproximación cognitiva, que traslada la cultura al interior de la mente ${ }^{17}$, hasta hoy -cuando de los postulados de Clifford Geertz suelen comprender la cultura desde una

17 "La cultura es una sociedad consiste en todo aquello que conoce o cree con el fin de operar de una manera aceptable sobre sus miembros. La cultura no es un fenómeno material: no consiste en cosas, gente, conductas o emociones. Es más bien una organización de todo eso. Es la forma de las cosas que la gente tiene es su mente, sus modelos de percibirlas, de relacionarlas o de interpretarlas."W.H.Goodenough (1957). 
aproximación simbólica ${ }^{18}$-, las distintas perspectivas convergen en insistir que el conocimiento de la cultura es un paso clave para comprender la conducta las instituciones sociales y las organizaciones. Esto, llevado al mundo policial, implica afirmar que hay una estrecha interdependencia entre el desarrollo de la organización de policía y su cultura.

Si bien asumimos y reconocemos que nos amparamos en una postura constructivista, conviene entender que la cultura es una variable interna en una organización, resultante de la interacción de individuos y grupos que generan cosmovisión, significados y conocimientos compartidos. En la práctica -y parafraseando a Aguirre $(2004,125)$ - la cultura en una organización policial puede ser entendida como:

Un sistema de conocimientos que proporciona a sus miembros un modelo de realidad a través del cual dan sentido a su comportamiento. Este sistema está formado por un conjunto de elementos interactivos fundamentales, generados y compartidos por la organización como eficaces para alcanzar sus objetivos que cohesionan e identifican, por lo que deben ser transmitidos a los nuevos miembros.

La cultura como forma de pensar, es vista en términos de interacción social, creativa y asociada a racionalidades particulares que emergen de la interacción de grupos con su entorno (Aguirre 2004).

En rigor, sostenemos que la organización es cultura, es decir, que las organizaciones policiales no tienen cultura, sino que -en verdad- son culturas. En consecuencia, estimamos que es un error actuar como si la cultura fuese una variable externa a la organización. Ella no es un traje o disfraz, no es anexa a ella, es verdaderamente ella. Es por ello que es sustantivo reconocer la cultura como:

a) Un conjunto de elementos fundamentales, generados y compartidos, por los miembros de un grupo u organización;

b) Que genera por la interacción del líder con el grupo. Las experiencias generados y luego compartidas construyen cultura organizacional;

18 La cultura es entendida como un proceso (o red, malla o entramado) de significados en un acto de comunicación, objetivos y subjetivos, entre los procesos mentales que crean los significados (la cultura en el interior de la mente) y un medio ambiente o contexto significativo (el ambiente cultural exterior de la mente, que se convierte en significativo para la cultura interior). 
c) Que precisa ser transmitida a los nuevos miembros del grupo, y esto se hace a través de la iniciación ${ }^{19}$, la enculturación ${ }^{20}$ y la socialización ${ }^{21}$;

d) Que, al ser compartida, genera identidad cultural y cohesión interna en la organización, y,

e) Que se espera que sea eficaz para alcanzar los objetivos de la organización, de lo contrario en ocasiones habrá que cambiarla (Aguirre 2004,159).

De acuerdo a Monjardet (2003), el análisis de la cultura profesional de los policías es el "talón de Aquiles" de todas las investigaciones sobre la policía. Esta afirmación no es exagerada, pues la cultura es verdaderamente el principio explicativo de las conductas. En rigor, en cualquier escenario -ya sea de cambio o desarrollo policial- la cultura es lo que importa, pues ella es un paradigma cognitivo para los miembros de la organización. Ella describe, explica y prescribe y consolida una visión de mundo, funda y recrea actitudes, valores, normas y creencias, conductas, entre otros componentes.

Desde esta perspectiva, estudiar y enfocarse en la cultura policial es un paso decisivo y estratégicamente relevante, porque la cultura es el núcleo profundo que hace inteligible la organización policial. Esta funciona como un filtro en diversos planos de las relaciones "policía -Estado" y "policía-sociedad", y especialmente en las representaciones y los habitus asociados a la práctica policial, la seguridad pública y ciudadana y la los grupos sociales que la rodean.

Valorando los aportes Bretas y Poncioni (1999), Reiner (2006) y Battibughi (2008), a los que se suman nuestras observaciones de caso, es indudable que a la hora de estudiar la policía y, asimismo, su cambio y desarrollo, deberíamos asumir las siguientes premisas:

1. Cada institución es una cultura organizacional ${ }^{22}$, que puede ser

19 La iniciación, a través de ritos de pasaje, busca introducir y marcar el ingreso y aceptación de un nuevo miembro a la organización y contribuye a la construcción de un "nosotros compartido", asegurando una "mutación ontológica” (del "no ser" a "ser policía”).

20 La enculturación pretende transmitir los componentes de la cultura organizacional, es decir, que el funcionario policial, se apropie - haga suya- y se empodere -conozca y domine- los códigos, símbolos, signos y categorizaciones que fundan la visión y la identidad de la organización.

21 La socialización busca desarrollar habilidades y competencias sociales, es decir que el individuo interactúe de manera eficaz en la organización.

22 En términos generales, podemos entenderla como el "conjunto de elementos interactivos generados y 
traducida como los valores, las creencias, los presupuestos básicos compartidos por los miembros de una institución y que de forma consciente o inconsciente forman e influencian las imágenes y opiniones sobre su propio ambiente o ambiente externo. La cultura policial representa un conjunto de saberes teórico-prácticos, reglas y valores, que definen un patrón específico.

2. Cada institución posee una cultura propia, que se compone de valores transversales o principios comunes en una organización policial -que, incluso, la observación empírica demuestra que son rasgos más recurrentes de lo que se podría suponer-. Estos son internalizados progresivamente al ingresar a la organización y sirven de guía inconsciente para las actitudes, decisiones y conductas. A través de un sistema de socialización, los miembros de la institución policial asumen un espacio simbólico que les da sentido y orienta sus acciones, lo que permite que ese espacio se reproduzca, mantenga y actualice. Así, las tareas, roles, ritos, símbolos, conocimientos y saberes, entre otros elementos forman parte del conjunto del sistema cultural de la policía.

3. La cultura policial es única, pero no es homogénea. Cada organización posee subculturas en su interior, que surgen experiencias comunes, de grupos que se reconocen como iguales y que comparten una posición específica en la organización, pudiendo incluso ser rivales o manifestar relaciones tensas y conflictos - generalmente son enclaves provenientes de cargos, funciones y desempeños compartidos, ordenados jerárquicamente.

4. La cultura de una organización policial incorpora, recrea y reproduce la imagen y la función que ella posee de si misma y de otras instituciones u organizamos del sistema con las que interactúa en el cumplimiento de sus funciones institucionales. Generalmente su identidad se construye en la oposición y la diferencia (alteridad).

5. Para la observación de la cultura policial es necesario considerar dos niveles de articulación: uno formado por la doctrina, los reglamentos y leyes y las políticas públicas; y otro conformado por la práctica y discursos presentes y dominantes en la institución, no

compartidos por los miembros de una organización al tratar de conseguir la misión que le da sentido a su existencia” (Aguirre 2004, 159). 
siempre efectivos, pero vitales para la comprensión de ellas. Este nivel de saber práctico se forma a partir de la interacción entre el conocimiento técnico del policía, las reglas formales establecidas y la práctica cotidiana. Así, no siempre ambos niveles se articulan de manera coherente y armónica.

6. La conducta y el accionar policial no pueden ser comprendidas cabalmente sin un estudio de la configuración y de la inserción del individuo en el grupo que posee un modelo burocrático particular una cultura característica. Se vuelve entonces fundamental pensar al policía no sólo como aquel individuo que está situado entre la institución y el ciudadano, sino también como un sujeto activo familiarizado con un mundo simbólicamente estructurado.

7. El análisis de la cultura policial debe realizarse tomando en consideración el contexto histórico y circundante, pues ella traduce la conducta de actores externos y revela los valores que sustentan la práctica y su identidad. De esta manera, la cultura de una organización puede contener o no un ethos laboral proclive a la aplicación de políticas de seguridad pública y ciudadana y estrategias de coproducción de la seguridad (orientación a la comunidad).

\subsection{Rasgos de la Cultura Policial.}

Si bien la existencia de una cultura policial, es decir, de un conjunto de saberes teóricos, técnicos y prácticos de ritos, símbolos, creencias y vocablos, etc., es el rasgo más reconocido, al mismo tiempo es el menos conocido. Esa es una paradoja de nuestras investigaciones sobre la policía, pues las explicaciones culturales -que no suelen dar únicamente los antropólogos- son las más aceptadas y, al mismo tiempo, las que más han ayudado a reconocer un espacio e identidad propia en las investigaciones sobre la policía, sus actuaciones y su organización.

Los estudios realizados hablan de ciertos rasgos comunes y de una heterogeneidad de construcciones que han hecho diversos investigadores en sus trayectorias investigativas en las últimas tres décadas. Es por esa razón que aquí se resume un conjunto de afirmaciones que relacionan cultura policial, organización y conducta individual o desempeño profesional, pues esto ayuda a demostrar la relevancia y necesidad de enfocarse en esta dimensión y en promover investigaciones de esta naturaleza 


\subsubsection{La Cultura Policial no es nn Estereotipo.}

Ella no debe ser vista como el fruto de una estructura y menos como un reflejo fiel de la sociedad. La cultura es, más bien, una construcción colectiva, que identifica a los policías que comparten ciertas creencias y categorizaciones derivadas de sus experiencias en el campo social y en su labor. El individuo -el policía- no es un ser pasivo que replica lo que "le viene dado desde afuera”.

En efecto, en ocasiones los propios policías construyen estereotipos de si mismos. Así, se trata entonces de actores y protagonistas que simbolizan, marcan y norman el espacio mismo del ser/quehacer policiaco. En las policías existe ritualización, códigos de conducta que prescriben las interacciones entre sus integrantes y otros. Hay doctrinas, reglas, fines, etc. Eso puede verse "desde afuera".

Pero, al mismo tiempo, existe una realidad que se deja ver en la práctica policial cotidiana, situaciones conflictivas y ambiguas son resueltas a través del saber práctico, hay autonomía y discrecionalidad no se dan sin un contexto de referencia, pues la adhesión a la cultura dominante de la organización genera un habitus y un campo que sirven para promover y mantener visiones sobre el trabajo policial y sobre cómo debe realizarse (National Research Council 2004, 131).

El estudio de la policía, como cultura organizacional, obliga a emplear una mirada fenomenológica - desde adentro- y una estrategia de investigación cualitativa generalmente emergente ${ }^{23}$.

\subsubsection{La Cultura Policial Específica, Atribuible a una Ocu- PACIÓN Y UNA ORGANIZACIÓN PARTICULAR.}

Existe consenso en señalar que la función y la práctica policial son más determinantes que el propio contexto en el que si insertan los policías

23 A pesar de los limites de una investigación cualitativa, también existe el peligro o riesgo de quedarse en la superficialidad de las manifestaciones, es decir, en lo visible, en lo verbalizable, en lo dicho, ocultando las prácticas reales y las paradojas. Es frecuente, por ejemplo, que las historias -narradas por los propios miembros de la policía en función o retiro- tiendan a distorsionar los hechos y estos sean reinterpretados siguiendo categorizaciones aprendidas y que ordenan la realidad en su propio beneficio. 
(National Research Council 2004, 131 y 133). Algunos rasgos son inherentes a la actividad policial. Skolnick (1966) afirmaba que la existencia de una cultura específica de las fuerzas policiales surgía mediante elementos permanentes de las actividades que realizan (peligro, autoridad, eficiencia).

Esta idea ha sido profusamente empleada, destacándose, por ejemplo, que el poder de policía, la presencia (potencial) del peligro o la imposición o ejercicio de la autoridad son los verdaderos elementos que ayudan construir la personalidad del trabajo policial, no como un fenómeno psicológico individual, sino como una cultura socialmente construida, derivada de procesos de socialización laboral.

Se afirma que la cultura policial varía, pero poco, pues se trataría de manifestaciones o respuestas adaptativas a un ambiente de trabajo caracterizado por la incertidumbre, el peligro, la desconfianza, la autoridad y el uso del poder coercitivo, que además sirve para manejar la tensión que origina el trabajo. Esta sería una respuesta o solución a problemas y tensiones inherentes al trabajo policial. Esta situación implicaría una serie de desafíos (como la presión por obtener resultados mediante el respeto a los procedimientos, a la ley y los derechos humanos y ciudadanos) que generan respuestas que, en la medida que van conformando matrices de sentido y patrones de actuación, hacen la cultura policial de la organización: reglas informales, ritos de pasaje, recetas para enfrentar las situaciones, que conforman y estructuran los modos de ser y hacer de los policías. Así, el policía vive la tensión permanente entre el ser y el deber ser, entre lo que las normas dictan y lo que las necesidades del momento imponen. De esta forma, las decisiones tomadas "en la calle" no siempre refleja el discurso legal, aún cuando al final éste pasa a ser dominante o referente obligado a la hora de informar. Esta situación que ha sido observada en distintos países (Azaola 2006, 11 y 12; Reiner 2006, 547; Suarez de Garay 2006, 6).

Los investigadores - anglosajones, españoles y brasileños - suelen subrayar que la profesión de policía involucra la posibilidad real de involucrarse en situaciones tensas peligrosas y que eso influye de manera significativa sobre la conducta de persona. Así, el peligro, el poder y la fuerza son aspectos fundamentales de la construcción simbólica de la actividad y desempeño policial. Éste, sumado al característico espíritu de cuerpo, que se apoya en una brecha que usualmente la diferencia y aleja de la sociedad civil, ayuda a construir la noción de que sólo un policía es capaz de entender el servicio policial. 
De ahí que uno de los rasgos más recurrentes sea el sentido de misión (Muniz 1999), que refuerza la idea de que no se trata apenas de un trabajo. Es un estilo de vida que se enriquece por y con el propósito que persigue: servir / controlar al ciudadano. El mandato policial es constantemente reforzado, en ritos que comienzan en los primeros años de formación, al iniciar el día y en la solemnidad de las ceremonias (Souza 2001). Es decir, desde la socialización en la organización se produce una subordinación a un "cuerpo" mayor, más importante que el propio. La organización se vuelve más importante que la persona y el sacrificio se justifica en función de la misión constitucional.

Lo anterior permitiría hablar de una identidad profesional universal de ser policía ${ }^{24}$ y de una visión de mundo particular, colmada de creencias, mitos y valores distintos a los de un ciudadano "no-policía". Un ejemplo de aquello es la creencia de que el trabajo policial no sólo es indispensable, sino también un estilo de vida insustituible ("si no lo hacemos nosotros, entonces quién?”).

\subsubsection{LA CULTURA POLICIAL NO ES HOMOGÉNEA Y QUE HAY DIFEREN- CIAS IMPORTANTES AL INTERIOR DE LAS ORGANIZACIONES Y ENTRE ÉSTAS (SUBCULTURAS).}

No hay duda que existe una diversidad de policías, modelos organizacionales y reglas informales distintas, dependiendo de la historia localsocial-institucional. No obstante, hay rasgos comunes. Las claves de la cultura policial contemporánea serían un conjunto de actitudes o universales de la cultura policial que ha sido destacada en diversos publicaciones, replicando -con variaciones- lo señalado por Skolnick (1966) hace cuatro décadas: i) La suspicacia y desconfianza en relación a los no-policías; ii) La solidaridad interna; iii) El aislamiento social; iv) El conservadurismo; v) El racismo; y, vi) El machismo. En este caso, la cultura muestra diferencias entre organizaciones y grupos de policías al interior de éstas.

24 "Independentemente das características organizacionais das polícias nos diversos contextos sociais em que se fazem presentes ou de seu caráter civil ou militar, há algo em comum na experiência ou atividade policial que acaba por favorecer a emergência de uma forma peculiar de conceber seu trabalho, sua relação com a sociedade e com a população criminosa. Nesse sentido, a cultura policial ultrapassa todas as fronteiras nacionais, constituindo uma identidade profissional internacional do ser policial. $\mathrm{O}$ substrato dessa cultura elementar do policial seria o compartilhamento de traços inerentes ao trabalho de combate ao crime, quais sejam, a presença constante do perigo, o mandato do uso da autoridade e da força coercitiva" (SOUZA y SAPORI 2001, 184). 
Si bien se trata de una materia no suficientemente estudiada en nuestro contexto latinoamericano, hay evidencia que lleva a pensar que hay tendencias cognitivas y estructuras de pensamiento -racionalidades- que son propias del policía, dadas las circunstancias en las que desenvuelven sus labores y que se vinculan con la socialización (Britz 1997, 127-146). Es decir, no se trataría de un fenómeno psicológico individual, sino de una respuesta a una combinación única de factores que se da en el desarrollo de la función policial: peligro, autoridad, presión por la eficacia, etc. De esta forma, la investigación ha llevado a sostener que habría personalidades ocupacionales en las organizaciones policiales vinculadas a los procesos de socialización (Mcnamara 1999, 6-9; National Research Council 2004, 131 y 132; Paoline 2004, 205-236; Reiner 2006, 552).

No obstante, las policías son verdaderos archipiélagos, culturalmente heterogéneos. Es por ello que, con mayor énfasis en algunos casos y con variaciones entre una y otra organización policial, se habla de subculturas policiales, que anidan en las organizaciones, dando vitalidad a los grupos internos ${ }^{25}$ y que reproducen sus habitus compuestos de categorizaciones y representaciones particulares, agregando un conjunto de clasificaciones y ordenamientos del mundo del policía y de los propios policías. De esta forma, se pueden reconocer diversas clasificaciones y categorizaciones:

1. la separación entre "la calle" v/s "lo administrativo-oficina";

2. el "mando superior" v/s el "subalterno";

3. la obediencia $\mathrm{v} / \mathrm{s}$ la independencia;

4. la discrecionalidad $\mathrm{v} / \mathrm{s}$ el fiel seguimiento de la norma;

5. el policía $\mathrm{v} / \mathrm{s}$ el paisano (civil);

6. el policía uniformado $\mathrm{v} / \mathrm{s}$ el no uniformado;

7. el policía dedicado a labores preventivas $\mathrm{v} / \mathrm{s}$ el detective $\mathrm{o}$ investigador;

8. el policía "operativo" v/s el "analista";

9. la "antigüedad" v/s el mérito;

10.lo "militar" (tradición castrense) v/s "lo civil"

11. las clasificaciones de los propios policías de sus pares en función de la forma cómo trabajan y se relacionan con el mando superior (poder), etc.

25 Son formas culturales que no tienen autonomía para vertebrar a un grupo autónomo (Aguirre 2004, 135). 
Mientras Reiner destaca que la cultura policial no es monolítica y que ella varía según las situaciones y contextos, Hagen (2005) también sostiene que ésta no agota todas las posibilidades de análisis de la actividad policial. Para ella la cultura policial está ligada a la situación de trabajo y a variaciones derivadas de distribuciones diferentes del capital social y la solidaridad interna, dejando de lado otros condicionantes como son, por ejemplo, los diversos intereses de la institución policial, los intereses de los policías y los conflictos con el poder político.

Hay, en definitiva, diversos planos de normas vigentes y que enmarcan la actuación del policía: "reglas operativas" -basadas en la experiencia y el saber policial-, lineamientos formales -que sancionan o inhiben de manera efectiva-y "reglas oficiales" - que no llegan a ser relevantes en la práctica, pero que son referentes claves en el discurso oficial de una policía (Smith 1983).

\subsubsection{La Cultura Policial, las Creencias y el Aislamiento Social.}

Se ha destacado que el mapa social de los policías distingue entre aquellos personas, situaciones y lugares que pueden representar u problema o no. Con frecuencia, la cultura policial tiende a no ser muy transparente a los ojos externos y a evitar rendir cuenta ante "extraños" o "ajenos" a la organización. Incluso los ciudadanos son objeto de diferenciación según el grado de peligro y amenaza que representan y las situaciones en las que se desarrolla la interacción o encuentro (Oliverira, 2007, 91). Se ha destacado que la actividad policial tiene un sello discriminatorio, que no puede o debe ser ignorado: la sospecha. El policía se mueve por la desconfianza, la estigmatización y los prejuicios compartidos por la cultura policial y gran parte de la sociedad. En este contexto, destacan las investigaciones que publican Ramos y Musumeci (2005, 71-100) sobre la policía militar de Rio de Janeiro.

En ocasiones también se subraya la opacidad de las policías a la indagación de investigadores "externos", siendo éstas en la mayoría de las ocasiones refractarias a dichos esfuerzos. En Argentina, por ejemplo, donde los estudios se concentran en la Ciudad y Provincia de Buenos Aires, y la Provincia de Santa $\mathrm{Fe}$, se señalan prácticas tanto de las autoridades políticas y policiales como de la cúpula policial que valora positivamente el secreto, el silencio y la simulación -la denegación de acceso a la información estadística y a documentos institucionales-, o la prohibición a los funcionarios de hablar de asuntos referidos a la institución sin autorización del superior jerárquico 
(Sozzo, 2005, 11). Cuando ello ocurre, los policías se convierten en incomprendidos e incomprensibles para el resto de la sociedad ${ }^{26}$.

\subsubsection{Cultura, socialización, entrenamiento y conducta FUNCIONARIA.}

Los elementos estructurantes en la socialización y formación policial son sustantivos. Los procesos de socialización y de construcción de identidad son decisivos y provocan cambios en las orientaciones valoricas (McNamara 1999, 6; Stradling et al 2006, 131-147). La investigación sugiere que el recluta o aspirante a policía ingresa con altos ideales y altos estándares éticos. Ya en los primeros años de instrucción policial se producen ligeros cambios en las actitudes y valores, cambios que se acentúan con los años (Ford 2003, 84-110). Asimismo, la socialización en ambientes laborales es un proceso continuo que lleva a ajustes permanentes cuyo éxito repercute en el bienestar personal y en actitudes positivas hacia el trabajo (Bravo et al, 2004, 17-33).

Roberto Kant de Lima (2004), investigador brasileño instaló un importante punto en el debate sobre la socialización del policía y su entrenamiento. Según él, cuando se cuestiona el desempeño de los policías se acostumbra relacionar el mal desempeño con la mala preparación (o la falta de ella) y atribuir ésta a una mala calidad de la formación de origen. A pesar de que en muchos casos la relación sea procedente, sobre todo en el uso de arma de fuego, el autor indaga sobre si realmente el mal desempeño en general es resultado de mala preparación o de la falta de ella, o si no resulta de factores de otro orden. Y pregunta enseguida: jaquello que se está llamando de mal desempeño es realmente eso o se trata de un desempeño según un modelo que, en su raíz, legitima determinadas acciones?, aquellas que son las esperadas por la sociedad y sus autoridades.

En la misma línea Muniz (2001), que afirma que las policías pasan por dilemas y paradojas en su formación educacional. Según la autora, entre las cuestiones más candentes que movilizan el debate público sobre reforma de las policías brasileñas, se destaca el proceso formativo de los policías militares.

26 Estas imágenes culturales hablan de una relación profundamente conflictiva que alimenta, decisivamente, las expectativas, las formas y los modos de ser policía. Pero también los modos en que una institución y una cultura del orden comparten con la ciudadanía, con los otros una fluidez entre la norma y la anomia que termina por dibujar un territorio social contradictorio, ambivalente y paradójico. 
Nótese que, salvo raras excepciones, las principales críticas de la población y de los grupos civiles organizados señalan la brutalidad policial, de uso excesivo de la fuerza y la discrecionalidad del poder de policía, como los efectos perversos de la "falta de preparación" y de la "baja calificación profesional" de los policías militares. Se reportan, por lo tanto, la inconsistencia entre la misión de los policías de "servir y proteger" al ciudadano preservando un orden público democrático y contemporáneo, y los conocimientos, técnicas y hábitos aprendidos por los Policías Militares, que todavía estarían reflejando las doctrinas.

La socialización y el entrenamiento para desempeñarse en un rol ocupacional no acontecen de la misma manera. Por una parte, lo formal y lo informal suelen dictaminar orientaciones inconsistentes. ¿Por qué, muchas veces, el conocimiento que se aprende en las academias no se traduce en una práctica diaria profesional? y ¿qué viven los policías en las calles y por qué esta experiencias muchas veces no son compatibles con lo que se enseña y utiliza en las academias de policía?, son interrogantes que ponen en el debate la relación entre socialización y enculturación y profesionalización de la policía. En la actualidad en los países latinoamericanos existe una gran disparidad de modelos educativos, que atienden desde luego, a las características socio-jurídicas de cada nación. Sin embargo, es posible que se encuentren más semejanzas que diferencias y que los desafíos en modelos y criterios de formación sean similares, así también la investigación sobre estas materias. En este contexto, la relación entre modernización y reforma en la educación ha sido un paso decisivo en los procesos de cambio organizacional llevados a cabo desde la década de los noventa en la policía australiana (Casey 2001, 175) ${ }^{27}$.

\subsubsection{LA CULTURA POLICIAL ES UN FACTOR DECISIVO QUE PUEDE CON- TRIBUIR O EVITAR EL COMPORTAMIENTO IRREGULAR DEL POLICÍA.}

La literatura anglosajona y la observación en países latinoamericanos destacan las conductas desviadas como uno de los focos más problemáticos de la praxis policial, como exploran los estudios del Barómetro de las Américas (Cruz 2009; Orces 2008). Diversos estudios correlacionan ambas variables (Mcnamara 1999, 9-10; Kutnjak 2005, 63-96) y se han destacado

27 Casey, John; Las reformas en la formación de la policía en Australia. Revista Catalana de Seguretat Pública, 2001, Vol. 9, pp.169-184. 
que la poca visibilidad y el escaso desarrollo de la supervisión y control social externo o vigilancia civil se transforman en fuentes potenciales de desviación en el ejercicio de la labor policial, como destaca Hubert Williams (2002), Presidente de Police Fundation ${ }^{28}$.

En los países anglosajones -Estados Unidos e Inglaterra-, las observaciones sobre la cultura policial surgen tan pronto se realizan indagaciones sobre las actividades de los policías y se constata la brecha entre las reglas y normas de procedimientos y las actuaciones mismas, es decir, cuando se comprueba que no existe un isomorfismo entre la práctica policial y la norma, y las contradicciones entre el ser y el hacer, así como entre el decir y el no hacer, se vuelven evidentes. Esa distancia surge, según afirma el consenso general, como fruto de la discrecionalidad en la que debe trabajar el policía y respuesta a la tensión entre el control del delito y los procesos o directrices de la legalidad exigida. Es un hecho conocido que la praxis policial goza de un importante grado de autonomía y que "la calle manda" ${ }^{29}$.

En este sentido, la cultura policial puede ser comprendida como el conjunto de matrices de actuación no escritos, en el cual se cruzan las prácticas cotidianas, la legalidad y los reglamentos, como también los proyectos y objetivos del Estado, además de las presiones que provienen de la sociedad. Eso significa que no siempre el parámetro legal es visto como el principal orientador de las acciones policiales, como reveló el estudio del Servicio de Policía de Queensland, Australia ${ }^{30}$.

Con frecuencia se señala que la violencia, la conducta desviada y la corrupción policial -por ejemplo-son asumidas como actuaciones que obedecen a una cultura policial dominante y que el problema no radica en la existencia de un espíritu de cuerpo en la organización, sino en el ocultamiento de la conducta desviada (código del silencio) y el abuso de poder

28 Williams, Hubert; Core factors of police corruption across de the world; en: Forum on Crime and Society, 2002, Vol. 2, No 1, pp.85-99.

29 Por ejemplo, la discrecionalidad del policía -dadas las situaciones que debe enfrentar- es un factor característico que no puede subestimarse, que ha sido destacada por diversos investigadores. Ésta pone en evidencia que la actuación policial no sólo no es mecánica, sino que también es esencialmente práctica y orientada a la acción, lo que no significa que la norma siempre quede de lado.

30 Ede, Andrew; The prevention of police corruption and misconduct: a criminological analysis of complaints against police. Tesis doctoral en Criminología y Justicia Criminal de la Griffith University, Australia, 2000, 290 pp. 
frente a la sociedad, como se ha destacado en relación al casos de algunas de las policías de Argentina ${ }^{31}$ o México ${ }^{32}$.

De esta forma, la exploración sobre la cultura policial muestran que hay patrones de conducta policial en una determinada época y que al averiguar hasta qué punto y por qué hay acciones que se alejan de la norma escrita, de la ley y de la deontología policial, el habitus y las representaciones sociales hacen posible una cultura que tolera y que las considerada normales o validas $\mathrm{y}$, en algunos casos, hasta necesarias.

\subsubsection{LA ACTUACIÓN POLICIAL DEPENDE DE LA CULTURA POLÍTICA Y ORGANIZACIONAL.}

La evidencia revela que la práctica policial es diversa y se vincula estrechamente a la cultura política local y la cultura organizacional, conceptos que había sido destacados por Wilson (Variety of Police Behavior, 1968), cuando analizaba la conducta organizacional del policía y señalaba la existencia de estilos distintos de actuación (legalista, vigilante y orientado al servicio). En el primer caso, la cultura política se refiere al poder, el ejercicio del liderazgo, la instrumentación de la autoridad (autoritarismo u orientación democrática) y a las expectativas sobre cómo deben materializarse los objetivos de un gobierno (gobernabilidad) y la comprensión sobre lo que legitima la actuación del Estado-Gobierno (democracia v/s autoritarismo):

"La policía suele ser un reflejo de la cultura general y sobre todo de la cultura politica de un pais. Comparte sus vicios y sus virtudes. Sise la quiere cambiar, hay que tratar de cambiar el espiritu de toda la administración pública e incluso de la sociedad" (Waldmann 1996, introducción)

Tres décadas después las investigaciones no sólo ratifican la relevancia de una aproximación cultural a la organización y a la práctica policial, sino

31 World Organization Against Torture (OMCT) y Centro de Estudios Legales y Sociales (CELS); Informe "Descripción de las prácticas a través de las cuales se ejercen la violencia institucional y no institucional en la Argentina y análisis de los factores que permiten y/o favorecen la victimización de sectores socioeconómicamente vulnerables, Buenos Aires, 2006, 282 pp.

32 A modo de ejemplo, corresponde citar las observaciones respecto de algunas policías en México "Encontramos al interior de las policías estructuras ilegales simultáneas que se montan sobre la estructura legal de la institución, de modo que se superponen los saberes para la ilegalidad sobre los saberes legales. A través de estas estructuras simultáneas han prevalecido símbolos, valores y normas distintos de los que deberían regir a un cuerpo policial profesionalizado. A través de los mecanismos de lealtad, identificación, pertenencia y jerarquización se ha institucionalizado lo no escrito, lo no legal, la ley del más fuerte y de los veteranos” (Suarez de Garay, 2006, 5). 
que también subrayan que las variaciones dependen de contextos sociales y políticos específicos en los que se insertan los policías. David Klinger (2004) destaca que éstas no son entes aislados y que los factores organizacionales y ambientales determinan la conducta de los policías ante los ciudadanos, enfatizando que fuerzas externas -como las directrices de la política- efectivamente penetran e influyen sobre la policía. Evidencia más reciente, en el marco de la comparación intercultural, demuestra que las creencias ocupacionales de los oficiales de policía, las expectativas y las perspectivas son influenciadas principalmente por los contextos sociales, políticos, culturales y organizacionales en los que trabajan (Sun y Chu 2008, 5-23).

En consecuencia, hay buenos argumentos para sostener que las estrategias policiales pueden verse favorecidas o afectados por las elites de poder, tanto al interior de la organización como fuera de ellas (Reiner, 2006, 553) y que, por ejemplo, la orientación al ciudadano es clave (Tudela 2004). La cultura política democrática es más decisiva para las estrategias policiales, el cambio organizacional y la innovación (Greene 2006; Paolline 2004, 209)33. En esta dirección apunta la investigación de Souza (2001), Quintana et al (2003), Kant de Lima (2003) y Beato y Marinho (2006) en Brasil.

Como señala Battibugli (2008), de la Universidad de Sao Paulo, el concepto de cultura policial sirve para comprender los valores y las prácticas institucionales que forman la identidad del profesional y que ella está inmersa en un cuerpo social reflejando sus valores y conductas. De este modo, es preciso analizar la interrelación existente entre la cultura policial y las particularidades de la sociedad (brasilera) en el trato con los ciudadanos.

Aunque hay rasgos y tendencias comunes, que dan señas de una cultura policial "básica", el estilo y la intensidad de las manifestaciones varían. Hay contextos sociales y políticos que explican esas diferencias. La cultura policial es sensible a las presiones y estímulos de su entorno. Una variable estructural relevante es la reforma policial en América Latina. Ésta, con sus distintos niveles de desarrollo y expectativas locales, es un buen ejemplo de cómo la administración policial (que depende más del poder político de turno), puede propiciar cambios para promover la cultura de la legalidad o democrática.

33 Greene, Jack; La policía de proximidad en Estados Unidos: cambios en la naturaleza, estructura y funciones de la policía”, pp. 349-424; Justicia Penal Siglo XXI. Una selección de Criminal Justice 2000, Rosemary Barberet y Jesús Barquín (Edit.), Granada, 2006, 460 pp. 
En este sentido debemos insistir que cualquier reforma implica un cambio de paradigma en la organización, es decir, en la cultura policial, de manera tal que permita a la institución adaptarse a los principios y reglas del juego democrático. Desatender esa realidad se vuelve el talón de Aquiles de cualquier cambio en favor de una gestión policial eficaz y de calidad a los ojos de los usuarios de los servicios que prestar una organización.

Un hecho indiscutible es que en la medida que avanza la democratización de la sociedad, en tanto la cultura política de los ciudadanos e instituciones republicanas evoluciona, de la misma forma se producen cambios sustanciales en el funcionamiento de los órganos del Estado, luego, en la cultura organizacional de la policía y en la cultura política del policía.

\subsubsection{CULTURA POLICIAL Y CAMBIO ORgANIZACIONAL.}

En la última década se ha instalado con fuerza la convicción de que en muchos casos son necesarios cambios en la "cultura de la policía", ya que ella no es un accidente y menos un factor que pueda soslayarse. Nuestras indagaciones nos llevan a sostener que uno de los primeros estudios sobre policías realizados en Iberoamérica y que tiene como contexto el cambio en la organización fue realizado sobre una policía de Barcelona por Manuel Martín (1990) en un momento sociopolítico marcado por la democratización en España. En otro ámbito, al amparo de una crisis de legitimidad social, el estudio de Janet Chan (1997) sobre el racismo y la reforma policial en Australia entrega interesantes luces y examina cómo el cambio y la resistencia dentro de una organización de policía no sólo son complejos, sino también impredecibles. Ella sostiene que hay una estrecha interrelación entre las condiciones estructurales de trabajo, el conocimiento de la cultura policial y la práctica policial.

Aún cuando esa línea de pesquisa no ha sido explorada con la profundizada aconsejable en países de la región, recientes estudios demuestran que la cultura de la organización y su influencia en la conducta funcionaria es decisiva, especialmente en la ejecución de las estrategias policiales y el cambio en la organización, especialmente si implican una orientación comunitaria (Giacomazzi y Brody 2004, 37-55; Sollund 2007, 184-184). La construcción o búsqueda de sentido es un proceso que en los miembros de una organización involucra la explicación de su mundo. Esto es importante, porque -en 
ocasiones- la cultura dominante actúa como "filtro" o procesa las presiones dirigidas a mejorar el servicio policial como si fuesen verdaderas amenazas a la organización y a la identidad de la policía (se afirma que algunos cambios llevan a perder la "esencia de la función policial").

Esta situación es explicada por Chan (2007, 323-345) apelando a los conceptos de campo y habitus de Bourdieu, que ayudan relacionar la cultura policial y práctica y permiten describir cómo los oficiales traducen los cambios en "formas compartidas de entendimiento" y los valores que informan su habitus laboral. Cuando se enfrentan al cambio en su medio, los policías intentan construir sentidos (interpretaciones) de las incertidumbres, perturbaciones o problemas y "representan" sus interpretaciones sobre las situaciones para dar un sentido y orden a los acontecimientos. Los discursos que manifiestan la resistencia son relevantes. Así, en determinados contexto, la cultura policial es también un impedimento para el cambio organizacional en la propia policía. La resistencia -derivada de una matriz cultural que rechaza la innovación y la mejora continua es un aspecto observado en diversas policías del mundo (Chan 1997, Sollund 2007, Loftus 2008).

En esta misma línea la cultura policial dominante también puede representar un obstáculo para la responsabilización, la vigilancia civil o control externo y la rendición de cuentas (accountability policial). Por ejemplo, el estudio el cambio en la Policía de Hong Kong hacia una institución más profesional y muestra como la tradición paramilitar limita el cambio. Cuando ocurrieron los cambios, estos fueron inducidos de manera extra institucional y fueron lo suficientemente fuertes para vencer los obstáculos institucionales. Dicho estudio ayuda a comprender el cambio organizacional en una institución que mostraba un sello colonial, represivo y corrupto (Jiao et al, 2005, 38-57).

De cualquier forma, la evaluación de los procesos de cambio organizacional emprendidos en algunas policías revela que la resistencia de la cultura policial tradicional es un factor clave, cuyo impacto sólo puede reducirse en la medida que -más existe un compromiso sólido y el apoyo de todos quienes ejercen poder y autoridad en la organización (alineamiento), es decir, de los liderazgos policiales- también se trabaja sobre la misma. La experiencia de trabajo en la Policía de Investigaciones permite afirmar que la complejidad del cambio, en cualquiera de sus dos adjetivos -organizacional o cultural- no puede ni debe subestimarse. 
Como sugiere Patricio (2009), hay una tendencia a creer los procesos de modernización o reforma institucional de las policías se anclan o dependen de cambios de los programas de estudio. Sin embargo, el cambio de actitud, del estilo profesional, de visión y la transformación de la cultura organizacional son procesos más complejos y que no dependen en estricto rigor del simple cambio de programas. Definitivamente, el cambio de cultura organizacional en una institución policial tiene como base el cambio de la estructura en la formación del policía, pero sería un error atribuir a los procesos de formación que se dan al inicio de la carrera policial un efecto que supere el peso de la cultura organizacional de una policía. Parece oportuno preguntarse entonces si ¿el cambio de cultura puede ser conseguido a través de la reforma de los programas de estudio de las academias?, o bien ¿hay factores de otro orden ( $y$, por lo tanto, estrategias pedagógicas) que deben ser considerados, ya que generan visión de mundo, ideologías y, consecuentemente, prácticas cotidianas?.

Independiente de su origen y razón, el cambio en la organización -entendido ya sea como reforma o modernización- apela a una misma necesidad: intervenir sobre la cultura policial, de forma que ella facilite la adopción de nuevas orientaciones valoricas, nuevas directrices de actuación y nuevas pautas de conducta. El verdadero cambio cultural en la policía implica una transformación de la matriz de sentido dominante en la organización. Esta forma de mirar el desarrollo de la policía ha sido abordada por la Policía Nacional de Colombia (Serrano, 2004; Álvarez 2007; Acero 2007) y la Policía de Investigaciones de Chile (Herrera y Tudela 2005; Policía de Investigaciones de Chile 2006) en el contexto de los programas y planes dirigidos al cambio en la organización. Las estrategias de modernización de ambas policías conciben el cambio en la organización como un cambio cultural y viceversa, es decir, el cambio organizacional es igual al cambio cultural en una institución policial. Otras policías, más recientemente, también declaran compartir la misma convicción, como es el caso de las Policías de República Dominicana (Pérez 2005,2) y Panamá (Bares 2003).

\section{Conclusiones y Sugerencias.}

Aquí se ha explorado la contribución de algunas disciplinas de las ciencias sociales, en especial la antropología, a la comprensión de la policía -como organización y praxis-. De esta forma, arribamos a dos tipos de con- 
clusiones: las relativas a la investigación social, por una parte, y aquellas derivadas de la antropología, por la otra.

En nuestra opinión, las ciencias sociales tienen mucho que aportar. Contribuyen con un tipo de conocimiento y reflexión necesaria en el marco de las problemáticas sociopolíticas del desarrollo de las sociedades y comunidades. Ellas ayudan a descubrir o construir -según sea el paradigma que se emplee- y a revelar ciertas situaciones verídicas decisivas para quienes toman decisiones, diseñan políticas criminales y de seguridad y, especialmente, contribuyen a la coproducción de la seguridad ciudadana. La policía es, sin duda, un factor clave en esa dinámica.

En este análisis se identifican algunas debilidades y fortalezas de la pesquisa social aplicada a la policía. Más allá de lo señalado en párrafos anteriores, hay una serie de desafíos, que se describen a continuación:

a) La generación de estudios sobre la policía constituye un paso fundamental desde la perspectiva de la introducción de nuevos referentes axiológicos de la actuación policial. Las sociedades cambian y también sus policías. De la misma forma, las ciencias sociales deben acompañar esa transición. No obstante, el escaso desarrollo de la teoría, la debilidad -en términos de validez- de los tipos de diseño de investigación (exploratorios, descriptivos, cuasi experimental) y el limitado potencial de generalización -a partir de los hallazgos alcanzados-, constituyen retos epistemológicos.

b) La observación desde afuera es útil, pero insuficiente. Es necesario abordar la organización policial desde "adentro", rescatando el punto de vista del individuo en la organización, reconociendo las categorías propias y estructurantes de la labor policial.

c) El desarrollo de investigaciones con un enfoque situacional y constructivista es prioritario. Este ayuda a explorar y estudiar -por ejemplo- el impacto de la capacitación y la profesionalización, como también los efectos del mayor control respecto de la conducción y el trabajo policial (vigilancia policial, control social externo, responsabilización o accountability) y los mayores requerimientos de legalidad de sus actuaciones. La escasa atención de los tipos de discreción policial "en la calle", que es lo que importaría a quienes formulan e implementan políticas y estrategias relacionadas con la 
labor policial, a los medios y a la ciudadanía, hacen más necesario aún este tipo de averiguaciones.

d) La relación entre las prioridades organizacionales de la policía y el ambiente externo en el cual opera es un campo necesario a explorar. Como señalan Zhao y Hassell (2005: 426), en la medida que entramos en el siglo XXI, debemos internar mejorar nuestra comprensión sobre la relación entre las organizaciones policiales, las comunidades y las estructuras de gobierno local. La exploración sobre la policía -como organización y praxis- precisa la generación de conocimiento para la mejora continua de la calidad del servicio al ciudadano. En este contexto, la interdisciplinariedad es una aproximación necesaria, a fin de que las actividades investigativas y sus hallazgos no se produzcan en forma aislada, dispersa y fraccionada.

El trabajo interdisciplinario es decisivo para el desarrollo del conocimiento sobre la policía. Como objeto y campo de pesquisa, no se trata de un campo reducido ni exclusivo. Esta forma de trabajo es necesaria y más fructífera, dada la naturaleza de la policía y la praxis cotidiana.

Por otro lado, en cuanto a la antropología, ella ayuda a comprender de qué está hecha la policía:

a) Ella sirve para a entender cómo la cultura policial es una variable determinante en los distintos contextos en los que se desenvuelve la actividad policial y cuán decisiva es en una organización para los múltiples propósitos que vinculan a la policía con su entorno: la sociedad y la política.

b) La investigación sobre la policía con un enfoque sociocultural puede ayudar -de hecho así es- en la generación de información y conocimiento práctico sobre los procesos subjetivos y colectivos que inciden y filtran la gestión, la praxis policial y el mejoramiento continuo de la función policial. No obstante, se debe indagar aún más en la dimensión cultural y los contextos socio-institucionales, y consolidar las herramientas conceptuales para la interpretación de la cultura policial, especialmente cuando se trata de un cambio organizacional, a la luz de procesos de modernización o mejoramiento de las estrategias policiales y la relación de la policía con la comunidad. 
Sin duda, debemos ir más allá de la comprensión de esa realidad. También precisamos avanzar en la construcción de un conocimiento aplicado para el diseño de estratégicas de desarrollo organizacional basadas en la evidencia. A veces es difícil trazar la línea de división entre la investigación aplicada y la no aplicada: la teorización abstracta a veces tiene aplicaciones prácticas importantes, como es, por ejemplo, reflexionar sobre la cultura organizacional y averiguar las diferencias y las similitudes socioculturales en una organización de policía pueden ser los principios a los que deba ajustarse un programa que busca un cambio planificado en una organización de policía.

Como señala Gravano (2008), la antropología proporciona algunos conocimientos prácticos para construir en forma concreta opciones y alternativas de mejoras organizacionales. Los instrumentos de acción propios de esta disciplina se enfocan en los mundos culturales que coexisten en las organizaciones y que posibilitan u obstaculizan su funcionamiento.

Siguiendo esta línea de razonamiento, y de acuerdo al estado del arte en algunos casos específicos -como la Policía de Investigaciones de Chile- la antropología - enfrenta al igual que las demás disciplinas sociales- el reto de contribuir en la generación de un conocimiento científico que permita en nuestros países el desarrollo de la policía y de su misión. La cultura policial es fundamental en la organización y su influencia en el individuo no puede ser puesta en duda, más aún hay creciente evidencia que demuestra su impacto en las estrategias policiales y su papel en el cambio de una organización.

Desde la perspectiva en que afirmamos que la organización policial es una cultura, el cambio -cultural u organizacional- puede ser fruto entonces de un proceso natural "evolutivo" o bien el producto de una gestión de cambio, es decir, de una estrategia planificada de transformación de la organización.

Así, la "ingeniería" del cambio cultural es el trabajo sobre las interacciones, procesos y factores claves de la organización (Hart 1996), que inciden en la tarea por alcanzar la misión ${ }^{34}$, de tal forma que la visión no sería más que el instrumento que visibiliza esta agenda de desarrollo (es el imaginario cultural de cualquier grupo que posee identidad propia).

La cultura debe apreciarse en términos de su funcionalidad para alcanzar la misión. Así, ella cohesiona, identifica y es eficaz en el logro de los obje-

34 La misión es el motor que impulsa la interacción grupal, es la razón de ser de la organización. 
tivos. De esta forma, es una condición exigible que facilita o dificulta el logro de la misión. De lo anterior se desprende entonces que es necesario estudiar la eficacia de la cultura organizacional en función de la misión y la visión.

Es aquí, en consecuencia, donde las ciencias sociales, en particular la antropología, muestran su mayor valor para el desarrollo policial. Un cambio planificado, un plan de desarrollo institucional, un plan estratégico, una política y un plan de seguridad pública y ciudadana, demandan cambios en las instituciones y una cultura organización favorable a esa misión o propósito.

Las pesquisas demuestran que en las organizaciones las creencias, valores y prácticas cotidianas sobre el "buen desempeño", por ejemplo, son profundas y que éstas pueden actuar como dique de contención de un cambio que las haga funcionar mejor: Hay núcleos de creencias que bloquean las posibilidades de cambio organizacional: ¿cómo detectar esa situación? y ¿cómo superarla?.

En este sentido, la pesquisa social y la antropología aplicada se ocupan de averiguar o generar conocimientos que tienen aplicaciones prácticas. Se trata de estudios con un claro interés en fines inmediatos. Ese ha sido una de las razones que dieron origen a la creación de CIDEPOL -compuesto por sociólogos, antropólogos, psicólogos- en la Policía de Investigaciones de Chile. Con un enfoque interdisciplinario el papel de los investigadores ha consistido en buscar o generar el conocimiento para alcanzar los fines del plan estratégico -que promueve un cambio organizacional-, y apoyar el diseño, ejecución y evaluación de proyectos e intervenciones. Es decir, se trata de investigaciones que contribuyen a la ejecución de un programa.

Es por ello que -en un ejercicio de reflexión con una perspectiva de anticipación y a la luz del estado del conocimiento producido adquirido en la última década - nos parece que surge una agenda de investigación y desarrollo, sobre la base de -al menos- cuatro aspectos-interrogantes para la averiguación de la cultura policial:

a) Evaluar mejor el impacto de la cultura policial sobre la práctica y viceversa;

b) Explorar las dimensiones subjetivas y culturales de la relación entre la policía -como objeto de intervención- y el policía -como sujeto de las estrategias policiales-;

c) Indagar sobre las variables culturales y sociales determinantes de la eficacia policial (subcultura policial); $y$, 
d) Transitar desde el análisis del cambio cultural a la promoción de la cultura organizacional que facilita el desarrollo, la modernización y/o reforma en/de una organización policial (¿cómo cambiar y qué cambiar?).

Finalmente, la experiencia de trabajo como antropólogo en la Policía de investigaciones de Chile me permite afirmar que ningún cambio puede concretarse sin el protagonismo de los actores en juego. En esto, las culturas organizacionales son tan o más importantes que los procesos técnicos que acompañan - por ejemplo a la planificación estratégica y a los planes estratégicos que buscan el desarrollo en una organización/institución de policía.

Patricio Tudela Poblete (Ph.D.)

Dr. en Antropología Social (Alemania), Máster en Gestión y
Dirección de la Seguridad (España), Fundación Paz Ciudadana,
Chile. Profesor de Academia Superior de Estudios Policiales
De la Policía de Investigaciones de Chile y Profesor de Pre y
Postgrado de la Facultad de Ciencia Sociales de la Universi-
Dad de Chile.
E-mail: ptudela3@yahoo.es/ptudela@pazciudadana.cl.

\section{REFERÊNCIAS}

ACERO VELÁSQUEZ, Hugo; Reforma policial y uso legítimo de la fuerza en un Estado de Derecho. Una mirada a la experiencia de Colombia; en: Policía, Estado y Sociedad: Prácticas y Saberes Latinoamericanos. Haydée CARUSO; Jacqueline MUNIZ y Antonio CARBALLO BLANCO, Río de Janeiro, Publit, 2007, 101-110 pp.

ACHA KUTSCHER, Elisabeth; Cultura organizacional: vigencia e importancia de un concepto para la reforma de la policía. En: Debates en sociología, Lima, 2004, № 29, pp. 140-159.

ALVAREZ Martha, CARVAJAL Ciro, LEMUS Lucy, Ensayo "Cambio Cultural de la Policía en el Postconflicto”, Escuela de Estudios Superiores de Policía, Especialización en Seguridad, 2005. 
ALVES, Isaias; Cultura profissional e violência policial: uma discussão. En:

Estudos do Trabalho. Revista da Rede de Estudos do Trabalho, Año I - Número 1, 2007, 10 pp.

AMBOS, Kai; Juan Luis GÓMEZ y Richard VOGLER; La Policía en los Estados de Derecho Latinoamericanos. Bogotá, Ediciones Jurídicas Gustavo Ibáñez, 2003, 629 pp.

ARAYA, Sandra; Las representaciones sociales: Ejes teóricos para su discusión. Facultad Latinoamericana de Ciencias Sociales (FLACSO), Costa Rica, 2002, 84 pp.

ARIAS, Patricia y ZUNIIGA, Lisa; Control, disciplina y responsabilidad policial: desafíos doctrinales e institucionales en América Latina, FLACSO-Chile, 168 pp.

AZAOLA, Elena; Imagen y autoimagen del policía. La policía desde un enfoque antropológico. Serie Cuadernos de Trabajo del Instituto para la Seguridad y la Democracia A.C. (Insyde) No 14, México, 2006, pp. 9-12.

AZAOLA, Elena; Las debilidades de la fuerza pública de la Ciudad de México. Crimen, castigo y violencias en México. Elena Azaola, FLACSO Ecuador y Municipio Metropolitano de Quito, Colección Ciudadanía y violencias № 5, 2008, pp. 53-74.

BARES, Carlos; Relación policía-comunidad: un elemento para la modernización de la Policía Nacional de Panamá. Policía Nacional de Panamá, 2003, 15 pp. Ponencia en el Congreso Internacional del CLAD sobre la Reforma del Estado y de la Administración Pública (2003 Oct. 28-3 en Ciudad de Panamá).

BARROS, Lúcio; Polícia e sociedade: um estudo sobre as relações, paradoxos e dilemas do cotidiano policial. Tesis de doctorado del Departamento de Sociología y Antropología y del Departamento de Ciencia Política, Universidad Federal de Minas Gerais, 2005.

BATTIBUGLI, Thaís; Cultura policial paulista e estado de direito (pós1946 e pós-1985). III Seminário Internacional Organizações e Sociedade: Inovações e Transformações Contemporâneas. Porto Alegre, 12 a 14 de Noviembre de 2008. 
BEATO Cláudio y MARINHO, Karina; Estudo da estratégia organizacional de policiamento comunitário nas cidades de Belo Horizonte, Rio de Janeiro e Vitória. SENASP, Brasilia, Relatorio Final, 2006, 139 pp.

BRAVO, Margarita, GÓMEZ-JACINTO, Luis y MONTALBÁN, Manuel; Socialización policial: un estudio con una promoción de nuevo ingreso. En: Revista de Psicología Social, 2004, Vol. 19, No 1, pp. 17-33.

BRETAS, Marcos Luiz y PONCIONI, Paula; Cultura policial e o policial civil carioca. En: PANDOLFI, Dulce Chaves; CARVALHO, José Murilo de; CARNEIRO, Leandro Piquet; GRYNSZPAN, Máriio et aliii (Orgs). Cidadania, justiça e violência. FGV, 1999. p. 117-178.

BRIONES, Daniel; Presencia de Síndrome de Burnout en poblaciones policiales vulnerables de Carabineros de Chile. En: Revista Ciencia \& Trabajo. Año 9, № 24, Santiago 2007, pp.43-50.

BRITZ, Marjie; The police subculture and occupational socialization: Exploring individual and demographic characteristics. En: American Journal of Criminal Justice, Vol. 21, № 2, 1997, pp. 127-146.

CANDINA, Azun y LUNNECKE, Alejandra; Formación en derechos humanos y control institucional. Los cambios de la Policía de Investigaciones de Chile (1992-2002), pp. 119-166; Participación ciudadana y reformas a la policía en América del Sur. Hugo Frühling, y Azun Candina (Edit). Santiago, Centro de Estudios para el Desarrollo, 2004, 262 pp.

CARUSO, Haydée; MUNIZ, Jacqueline; CARBALLO BLANCO, Antonio; Policía, Estado y Sociedad: Prácticas y Saberes Latinoamericanos. Río de Janeiro, Publit, 2007, 605 pp.

CASEY, John; Las reformas en la formación de la policía en Australia. Revista Catalana de Seguretat Pública, 2001, Vol. 9, pp. 169-184.

CRUZ, José Miguel; Maltrato policial en América Latina. En: Perspectivas desde el Barómetro de las Américas, Vanderbilt University, 2009, No 11,8 pp.

CHAN, Janet B.; Changing police culture: policing in a multicultural society. Cambridge, Cambridge University Press, 1997, xi, 255 pp. 
CHAN, Janet; Making sense of police reforms. En: Theoretical Criminology, 2007, Vol. 11 No 3, pp. 323-345.

DELLASOPPA, Emilio; Estratégias e racionalidade na Polícia Civil do Estado do Rio de Janeiro. En: Violencia, sociedad y justicia en América Latina. Roberto Briceño-León (Compilador), Buenos Aires, CLACSO, 2001, pp. 201-227.

DIAS, Gilberto; A gestão da produção de segurança pública e a formação do oficial policialmilitar: o caso da polícia militar de Santa Catarina. Tesis de doctorado en Ingeniería de producción. Universidad Federal Santa Catarina. Florianópolis. 2002, 235 pp.

DIEZ CANSECO, Javier; Patios interiores de la vida policial. Ética, cultura civil y reorganización de la Policía Nacional. Fondo Editorial del Congreso del Perú. Lima, 2004, 221 pp.

DURÁN, Robert J.; Legitimated Oppression. Inner-City Mexican American Experiences with Police Gang Enforcement. En: Journal of Contemporary Ethnography, Vol. 38, № 2, 2009, pp. 143-168.

FORD, Robert E.; Saying one thing, meaning another: the role of parables in police training. En: Police Quarterly, Vol. 6 N $^{\circ}$ 1, 2003, pp. 84-110.

Frühling, Hugo y (edit.); Calles Más Seguras. Estudios de policía comunitaria en América Latina. Washington, Banco Interamericano de Desarrollo, 2004, 175 pp.

FRÜHLING, Hugo; Cambio e innovación en la policía latinoamericana. En: Violencia y policía en América Latina, Hugo Frühling, FLACSO Ecuador y Municipio Metropolitano de Quito, Colección Ciudadanía y violencias No 7, 2009, pp. 255-290.

GALEANO, Diego; En nombre de la seguridad. Lecturas sobre policía y formación estatal. En: Cuestiones de Sociología, Nº 4, 2008, pp.102-128.

GIACOMAZZI, Andrew y BRODY, David; The effectiveness of external assessments in facilitating organizational change in law enforcement. Policing: An International Journal of Police Strategies \& Management, Vol. 27, No 1, 2004, pp. 37-55. 
GRAVANO, Ariel; Antropología Práctica: muestra y posibilidades de Antropología Organizacional. En: Publicar en Antropología y Ciencias Sociales, 1, mayo, Colegio de Graduados en Antropología, Buenos Aires; 1992, pp. 95-126.

GRAVANO, Ariel; Mejoras organizacionales, 2008, 9 pp. En: http:// www.rau.edu.uy/fcs/dts/Mip2/mejoras.pdf (visitado el 28 de julio de 2009).

GREENE, Jack; La policía de proximidad en Estados Unidos: cambios en la naturaleza, estructura y funciones de la policía, pp. 349-424; En: Justicia Penal Siglo XXI. Una selección de Criminal Justice 2000, Rosemary Barberet y Jesús Barquín (Edit.), Granada, 2006, 460 pp.

GTZ Nicaragua; Modernización Institucional con Equidad de Género en la Policía Nacional de Nicaragua 1996-2005. Proyecto de Promoción de Políticas de Género, Managua, 2005, 146 pp.

HAGEN, Acácia Maria Maduro. O trabalho policial: estudo da Polícia Militar do Estado do Rio Grande do Sul. Tesis (Doctorado en Psicología), Universidad Federal de Rio Grande do Sul, Porto Alegre, 2005.

HAGEN, Acacia Maria Maduro; As classificações do trabalho policial. En: Revista de Estudos Criminais, v. 22, p. 121-148, 2006.

HAGEN, Acacia Maria Maduro; O trabalho policial: estudo da Polícia Civil do Estado do Rio Grande do Sul. São Paulo: IBCCRIM Instituto Brasileiro de Ciências Criminais, 2006. 300 pp.

HAGEN, Acacia Maria Maduro; Relações de gênero no trabalho policial. Encontro Anual da ANPOCS, 30, 2006, Caxambu, MG. 30 Encontro Anual da ANPOCS 2006, 2006.

HAGEN, Acacia Maria Maduro; Os policiais civis e os usos da violência. XXV Congresso da Associação Latino-Americana de Sociologia, 2005, Porto Alegre. XXV Congresso da Associação LatinoAmericana de Sociologia. Porto Alegre: Editora da UFRGS, 2005. pp. 363-363.

HAGEN, Acacia Maria Maduro; Trabalho policial, violência e masculinidade. IV Congreso Latinoamericano de Sociologia del Trabajo, 2003, Havana. Ponencias, resumenes, directorio de participantes. Havana: ALAST, 2003. 
HART, James; The management of change in police organizations. En:

Policing In Central And Eastern Europe: Comparing Firsthand Knowledge With Experience From The West. College of Police and Security Studies, Slovenia, 1996.

HERRERA, Arturo y TUDELA, Patricio; Modernización policial: La relación de la policía con la comunidad como campo de gestión y referente de cambio en la Policía de Investigaciones de Chile. En: Persona y Sociedad, Volumen XIX, N ${ }^{\circ}$, Abril 2005, Santiago, pp. 157-178.

IZQUIERDO, Santiago V.; Culturas institucionais e direitos humanos: uma contribuição da antropología. En: Políticas de segurança pública: dimensão da formação e impactos sociais. Jorge Zaverucha, et al. Recife: Massangana, 2002.

JIAO, Allan Y.; LAU, Raymond W. K. \& LUI, Percy; An Institutional Analysis of Organizational Change: The Case of the Hong Kong Police. En: International Criminal Justice Review. Vol. 15 N$^{\circ} 1$, 2005, pp. 38-57.

KAMINSKY, Gregorio; Cultura institucional policial y seguridad ciudadana en Argentina. En: Tiempos inclementes: culturas policiales y seguridad ciudadana. Universidad Nacional de Lanùs, Ediciones de la UNLa, 2005, 47-62 pp.

KANT DE LIMA, Roberto. Direitos Civis, Estado de Direito e "Cultura Policial”: a formação em questão. En: Revista Brasileira de Ciências Criminais. No 41. Año 11. São Paulo: Editora Revista dos Tribunais, 2003.

KING, William R.; Toward a Life-Course Perspective of Police

Organizations. En: Journal of Research in Crime and

Delinquency, Vol. 46 No 2, 2009, pp. 213-244.

KUTNJAK, Sanja; Fallen blue knights: controlling police corruption.

Oxford University Press, New York, 2005, 244 pp.

LOFTUS, Bethan; Dominant Culture Interrupted. Recognition, Resentment and the Politics of Change in an English Police Force. En: The British Journal of Criminology, Vol. 48, 2008, pp. 756-777. 
MCNAMARA, Robert; The socialization of the police. En: Police and policing: contemporary issues. Dennis Jay Kenney y Robert P.McNamara. Praeger Publisher, Wesport, 2da Edición, 1999, 1-12 pp.

MANNING, Peter; The study of policing. En: Police Quarterly, Vol. 8 No 1, 2005, pp. 23-43.

MARTIN FERNÁNDEZ, Manuel; La profesión de policía. Madrid, Centro de Investigaciones Sociológicas, Siglo XXI de España Ediciones, 1990, 206 pp.

MARTIN FERNÁNDEZ, Manuel; Mujeres policía. Madrid, Centro de Investigaciones Sociológicas, Siglo XXI de España Ediciones, 1994,159 pp.

MONJARDET, Dominique; O que faz a polícia: Sociologia da Força Pública. Coleção Polícia e Sociedade, São Paulo, EDUSP, 2003, 328 pp.

MUNIZ, Jaqueline. Ser policial é sobretudo uma razão de ser - Cultura e cotidiano da Polícia Militar do Estado do Rio de Janeiro. Tesis de Doctorado. Instituto Universitário de Pesquisas do Rio de Janeiro, 1999.

MUNIZ, Jacqueline. A Crise de Identidade das Polícias Militares Brasileiras: dilemas e paradoxos da formação educacional. En: Security and Defense Studies Review. Vol. 1. Winter 2001.

MUNIZ, Jacqueline; Dereitos humanos na policía. En: Segurança pública e violencia: o Estado está cumprindo seo papel?. Renato Sergio de Lima y Liana de Paula (Comp.), Editora Contexto, Sao Paulo, 2006, pp. 65-76.

MURPHY, Christopher; Police Studies Go Global: In Eastern Kentucky?. En: Police Quarterly, Vol. 8 No 1, 2005, pp. 137-145.

National Research Council of the National Academies; Fairness and effectiveness in policing. The evidence. Washington, 2004, $413 \mathrm{pp}$.

OLIVEIRA JUNIOR, Almir de; Cultura de policía: Cultura e atitudes ocupacionais entre policiais militares em Belo Horizonte, Tesis de doctorado. Universidad Federal de Minas Gerais, 2007, 212 pp.

OLIVEIRA, Adriano. Um estudo etnográfico da instituição polícia militar. En: Polícia e democracia: desafios à educação em direitos humanos. NEVES, Paulo S. et al. Refice: Bagaço, 2002. 
ORCES,Diana; Victimización por corrupción por la policía. En:

Perspectivas desde el Barómetro de las Américas, Vanderbilt University, 2008, No 3, 4 pp.

PAOLINE, Eugene; Rethinking Police Cultura: Officers`s Occupational Attitudes. New York, LFB Scholarly Publishing, 2001, 287 pp.

PAOLINE, Eugene; Shedding Light on Police Culture: An Examination of Officers' Occupational Attitudes. En: Police Quarterly Vol. 7 No 2, 2004, pp. 205-236.

PÉREZ, Manuel; Desafíos de la modernización policial en el marco de una política de seguridad ciudadana, Mayor General, Asesor Policial del Poder Ejecutivo República Dominicana San José, Costa Rica, 02 de noviembre de 2005, 19 pp.

PDI, Policía de Investigaciones de Chile; Plan Minerva. Una Misión Renovada. Santiago, 2006, pp. 48.

PDI, Policía de Investigaciones de Chile; Estudio descriptivo de la situación socio-laboral de la mujer policía. Jefatura del Personal, Santiago, 2009, 103 pp.

QUINTANA, Juan et al; Policía y democracia en Bolivia: una política institucional pendiente. Programa de Investigación Estratégica en Bolivia (PIEB), La Paz, 2003, 88 pp.

RAMOS, Silvia y Musumeci, Leonarda; Elemento suspeito: abordagem policial e discriminação na cidade do Rio de Janeiro. Civilização Brasileira, CESEC, Centro de Estudos de Segurança e Cidadania, 2005, 322 pp.

REINER, Robert; La policía y la actividad policiaca. Manual de

Criminología Mike Maguire, Rod Morgan y Robert Reiner (Edit); Oxford, University Press, 2006, pp. 525-586.

RICO, José María y SALAS, Luis; Seguridad ciudadana y policía, Madrid, Editorial Tecnos, 1988, 269 pp.

RICO, José María y CHINCHILLA, Laura; Las reformas policiales en América Latina: situación, problemas y perspectivas. Open Society Institute y Instituto de Defensa Legal, Lima, 2006, 245 pp.

RODRIGUES, Elizabeth; El enfoque de género en la formación de la Policía Nacional de Nicaragua. Policía, Estado y Sociedad: 
Prácticas y Saberes Latinoamericanos. Haydée CARUSO, Jacqueline MUNIZ y Antonio CARBALLO BLANCO. Río de Janeiro, Publit, 2007, pp. 363-368.

RODRIGUEZ, Alfredo; Sistema de Clasificación: caja negra de la corrupción policial. FLACSO-México, 2008, 104 pp.

SAIN, Marcelo Fabian; El Leviatan Azul. Política y Policía en Argentina. Editorial: Siglo XXI, 2008, 328 pp.

SAIN, Marcelo Fabian; Seguridad, Democracia y Reforma del Sistema Policial en la Argentina. Editorial: Fondo De Cultura Económica, 2002, 158 pp.

SAPORI Luís F. \& SOUZA, Silas B.; Violência policial e cultura militar: aspectos teóricos e empíricos. En: Revista Teoria e sociedade. Universidade Federal de Minas Gerais, No 7, 2001, pp. 173-214.

SCHMID, Carola; "Posibilidades de una investigación empírica sobre la policía en América Latina”. En: Waldmann, Peter. Justicia en la calle. Ensayos sobre la policía en América Latina, Konrad Adenauer-CIEDLA, Bogotá. 1996.

SCHMID, Carola; Korruption, Gewalt und die Welt der Polizisten: Deutschland, Chile, Bolivien und Venezuela im Vergleich, Vervuert Verlag, Frankfurt, 2007, 424 pp.

SERRANO, Rosso José (General); Modernización de la Policía de Colombia dentro del marco de la convivencia y la seguridad ciudadana, Comandante de la Policía Nacional de Colombia, 2004, $28 \mathrm{pp}$.

SIRIMARCO, Mariana; Acerca de lo que significa ser policía. El proceso de incorporación a la institución policial; en: Burocracias y Violencia: estudios de antropología jurídica; Sofía Tisconia (Comp.); Facultad de Filosofía y Letras, Univ. de Buenos Aires, 2004, pp. 245-280.

SIRIMARCO, Mariana; De civil a policía. Una etnografía del proceso de incorporación a la institución policial. Buenos Aires. Editorial TESEO, 2009, 184 pp. 
SOLLUND,Ragnhild; The implementation of Problem-Oriented Policing in Oslo-Norway: Not without problems?. En: Criminology

Research Focus, Karen T. Froeling (Edit.), Nova Science Publishers, 2007, pp. 175-194.

SOUZA, Rosânia R. Os processos de construção de identidade no trabalho do policial militar na atividade de policiamento ostensivo em Belo Horizonte. Tesis de la Universidade Federal de Minas Gerais, 2001.

SOUZA, Elenice; Organização policial e os desafios da democracia. En: Teoria e sociedade. № 7, Junio de 2001.

SOZZO, Máximo (Edit); Policía, violencia, democracia: ensayos sociológicos. Colección Ciencia y Técnica. Universidad Nac. del Litoral, 2005, 220 pp.

SUÁREZ DE GARAY, Maria Eugenia; De estómago, de cabeza y de corazón. Un acercamiento antropológico a los mundos de vida de los policías en Guadalajara, México. Tesis Universidad Autónoma de Barcelona. 2002.

SUÁREZ DE GARAY, María Eugenia; Márgenes de acción y poderes autónomos en el mundo policial, La policía desde un enfoque antropológico. Serie Cuadernos de Trabajo del Instituto para la Seguridad y la Democracia A.C. (Insyde) Número 14, México, 2006, pp. 3-8.

SUN, Ivan y CHU, Doris; A Cross-National Analysis of Female Police Officers' Attitudes in the United States and Taiwan. En: International Criminal Justice Review, Vol 18 № 1, 2008, pp. $5-23$.

SKOLNICK, Jerome; Justice without trial. Law enforcement in democratic society. New York: John Willey, 1966.

STRADLING, S.; CROWE, G. Y TUOHY, A.; Changes in self-concept during occupational socialization of new recruits to the police. En: Journal of Community \& Applied Social Psychology, Vol. 3, ํo 2, 2006, pp. $131-147$.

TONRY, Michael \& MORRIS, Norval; Policiamiento Moderno. Editorial de la Universidad de Sao Paulo, Sao Paulo, 2003, Serie Policía y Sociedad, $N^{\circ} 7 ., 645$ pp. Versión traducida de Modern 
Policing, University Chicago Press, Chicago. 1992.

TORRENTE, Diego; La sociedad policial: poder, trabajo y cultura en una organización local de policía. Centro de Investigaciones Sociológicas y Universidad de Barcelona, Madrid, 1997, 261 pp.

TUDELA, Patricio; La evaluación de la labor policial preventiva: Logros y aprendizajes recientes en Chile. Manuscrito presentado para publicación del Centro Internacional para la Prevención de la Criminalidad (Canadá) y el Programa de Seguridad Urbana de la Universidad Alberto Hurtado. Santiago, 2009, 47 Págs. (en prensa)

TUDELA, Patricio; Paradigmas policiales orientados a la comunidad en América Latina: entre realismo mágico y gestión de conocimiento. En: Revista Estudios Policiales, Santiago, No 3, Diciembre de 2008, pp. $11-34$.

TUDELA, Patricio; Sociedad y Policía: Desarrollo y retos de la función policial en las democracias latinoamericanas. Centro de Investigación y Desarrollo Policial, Policía de Investigaciones de Chile, Santiago, Diciembre de 2007, 37 pp. http://www.policia.cl/ cidepol/Biblioteca/Sociedad\%20y\%20Policía.pdf

TUDELA, Patricio; Sobre el control de la Policía de Investigaciones de Chile: dificultades y éxitos. Conferencia Internacional "Police Accountability and the Quality of Oversight. Global Trends and National Context". Altus Global Alliance. 19-21 Octubre 2005, La Haya-Holanda. 12 pp. http://www.policia.cl/cidepol/documentos. html

TUDELA, Patricio; Policiamiento Comunitario en Chile: Estrategias y Resultados. En: Memoria del Seminario Internacional "Ciudades más Seguras” Guarulhos, São Paulo, Brasil, Diciembre de 2003. Comp. Herbert Sanchez; Programa de Gestión Urbana, QuitoEcuador; Safer Cities Habitat-ONU; Foro Metropolitano de Seguridad Pública. 2004, pp. 134-145.

VIEIRA, Marcos Antonio; Planejamento estratégico e o alinhamento da polícia militar com o futuro: um estudo exploratório. Net Florianópolis, Diciembre, 2001. 
WALDMANN, Peter (Edit), Justicia en la Calle. Ensayos sobre la Policía en América Latina, Konrad Adenauer Stiftung, CIEDLA, ISLA., Buenos Aires, 1996. 444 pp.

ZHAO, Jihong "Solomon” y HASSELL, Kimberly D.; Policing styles and organizational priorities: retesting Wilson's theory of local political culture. En: Police Quarterly Vol. 8 No 4, 2005, pp. 411-430.

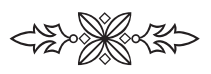

